\title{
A diagnostic assessment of the health system's response to female genital mutilation/cutting management and prevention in Kenya
}

Samuel Kimani

Chantalle Okondo

Population Council

Follow this and additional works at: https://knowledgecommons.popcouncil.org/departments_sbsr-rh

Part of the International Public Health Commons, and the Social and Behavioral Sciences Commons How does access to this work benefit you? Let us know!

\section{Recommended Citation}

Kimani, Samuel and Chantalle Okondo. 2020. "A diagnostic assessment of the health system's response to female genital mutilation/cutting management and prevention in Kenya," Evidence to End FGM/C:

Research to Help Girls and Women Thrive. New York: Population Council. 


\title{
Evidence to End FGM/C
}

Research to Help Girls and Women Thrive

\author{
A DIAGNOSTIC ASSESSMENT OF \\ THE HEALTH SYSTEM'S \\ RESPONSE TO FEMALE GENITAL \\ MUTILATION/CUTTING MANAGEMENT \\ AND PREVENTION IN KENYA
}

April 2020 


\section{A DIAGNOSTIC ASSESSMENT OF THE HEALTH SYSTEM'S RESPONSE TO FEMALE GENITAL MUTILATION/CUTTING MANAGEMENT AND PREVENTION IN KENYA}

SAMUEL KIMANI AFRICA COORDINATING CENTRE FOR THE ABANDONMENT OF FEMALE GENITAL MUTILATION /CUTTING (ACCAF) UNIVERSITY OF NAIROBI

CHANTALLE OKONDO POPULATION COUNCIL 
Evidence to End FGM/C: Research to Help Girls and Women Thrive generates evidence to inform and influence investments, policies, and programmes for ending female genital mutilation/cutting in different contexts. Evidence to End FGM/C is led by the Population Council, Nairobi in partnership with the Africa Coordinating Centre for the Abandonment of Female Genital Mutilation/Cutting (ACCAF), Kenya; the Global Research and Advocacy Group (GRAG), Senegal; Population Council, Nigeria; Population Council, Egypt; Population Council, Ethiopia; MannionDaniels, Ltd. (MD); Population Reference Bureau (PRB); University of California, San Diego (Dr. Gerry Mackie); and University of Washington, Seattle (Prof. Bettina Shell-Duncan).

POPULATION COUNCIL

Ideas. Evidence. Impact.
The Population Council confronts critical health and development issues-from stopping the spread of HIV to improving reproductive health and ensuring that young people lead full and productive lives. Through biomedical, social science, and public health research in 50 countries, we work with our partners to deliver solutions that lead to more effective policies, programmes, and technologies that improve lives around the world. Established in 1952 and headquartered in New York, the Council is a nongovernmental, nonprofit organisation governed by an international board of trustees. www.popcouncil.org

ACCAF is based at the University of Nairobi, College of Health Sciences, a premier institution for training of health care professionals, and a leader in health research and community services. Our goals and objectives are to: strengthen capacity for FGM/C research in Africa, implement FGM/C interventions, and improve care for women and girls who have undergone $\mathrm{FGM} / \mathrm{C}$, monitor progress in the abandonment of $\mathrm{FGM} / \mathrm{C}$, and inform policy programming on $\mathrm{FGM} / \mathrm{C}$ issues. www.accaf.org

Suggested Citation: Kimani, Samuel and Okondo, Chantalle. 2020 "A Diagnostic Assessment of the Health System's Response to Female Genital Mutilation/Cutting Management and Prevention in Kenya." Evidence to End FGM/C: Research to Help Girls and Women Thrive. New York: Population Council.

This is a working paper and represents research in progress. This paper represents the opinions of the authors and is the product of professional research. This paper has not been peer reviewed, and this version may be updated with additional analyses in subsequent publications. Contact: Dr Samuel Kimani, tkimani@uonbi.ac.ke or thuo.kimani@gmail.com.

Please address any inquiries about the Evidence to End FGM/C programme consortium to:

Dr Jacinta Muteshi, Project Director, imuteshi@popcouncil.org

Funded by:

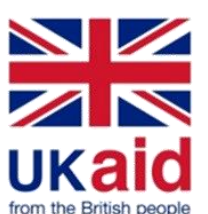

This document is output from a programme funded by UK Aid from the UK government for the benefit of developing countries. However, the views expressed and information contained in it are not necessarily those of, or endorsed by the UK government, which can accept no responsibility for such views or information or for any reliance placed on them. 


\section{Table of Contents}

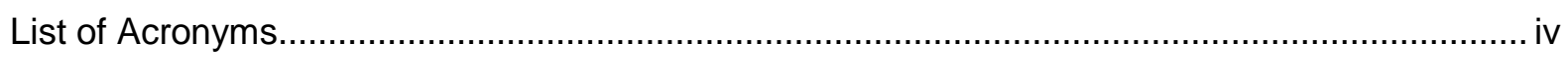

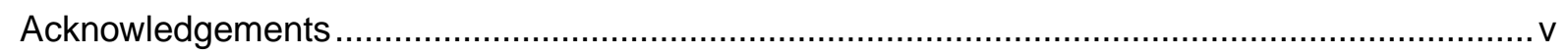

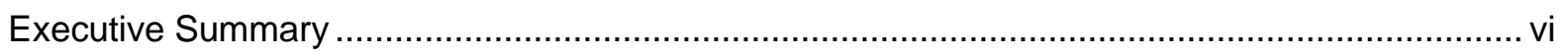

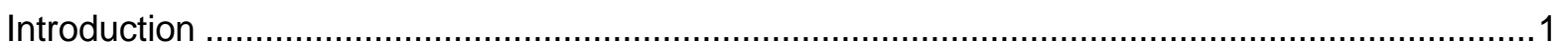

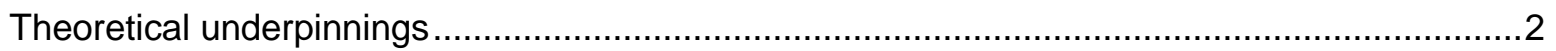

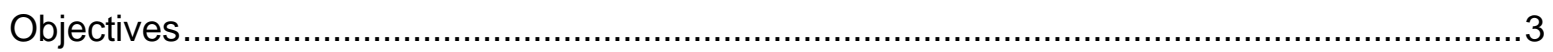

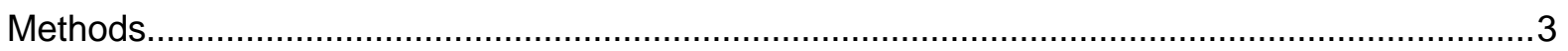

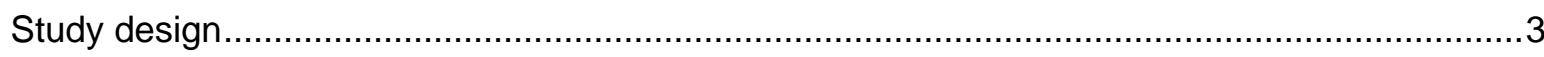

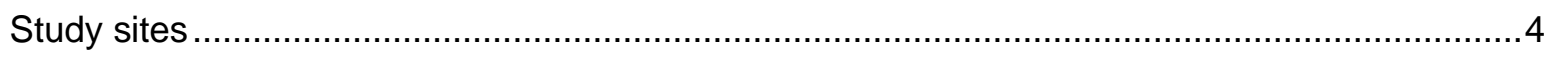

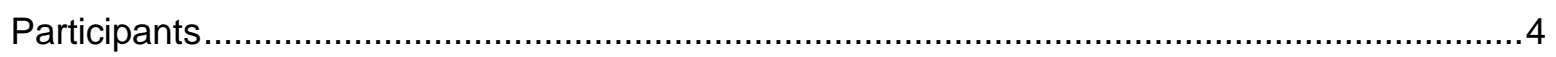

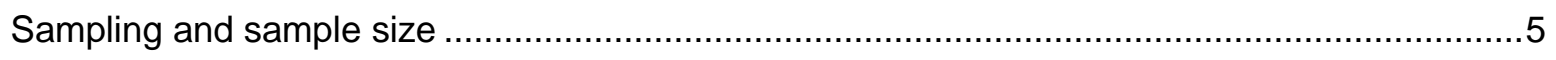

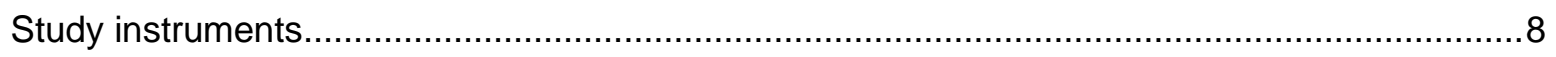

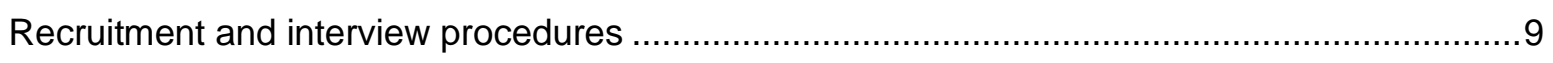

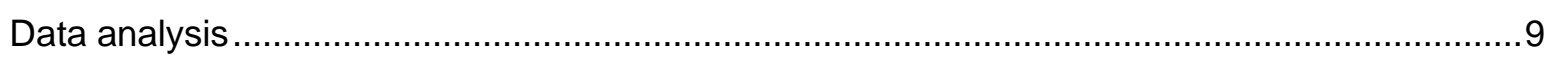

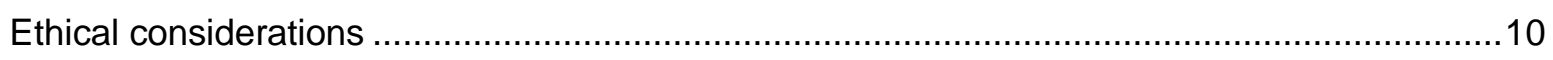

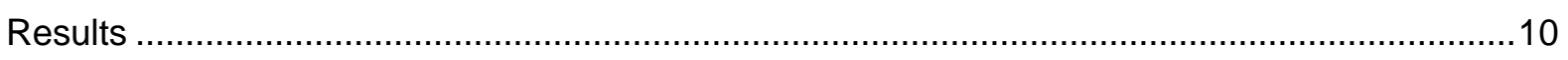

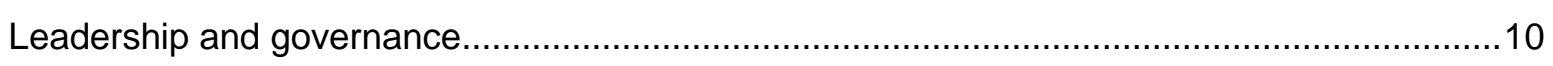

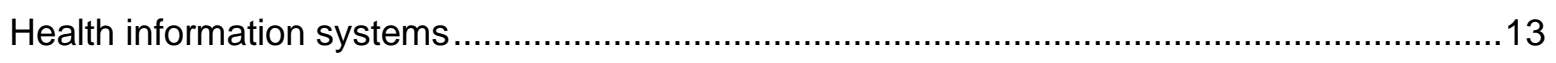

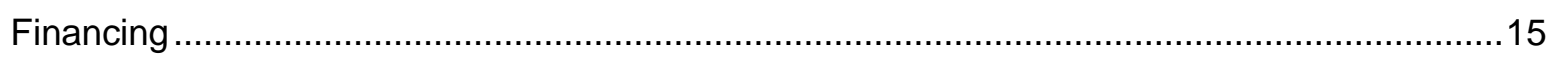

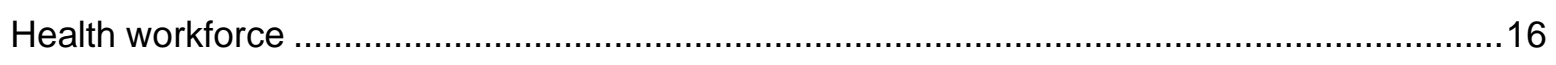

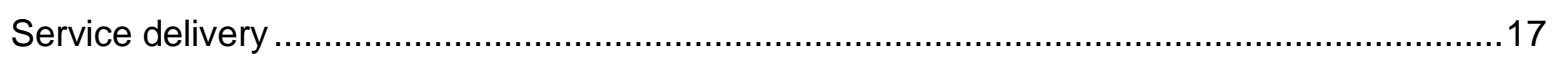

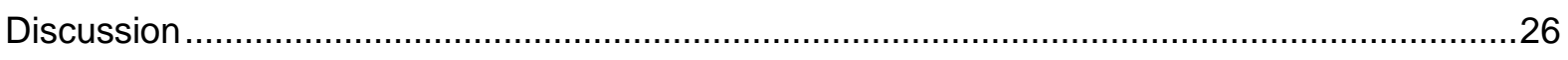

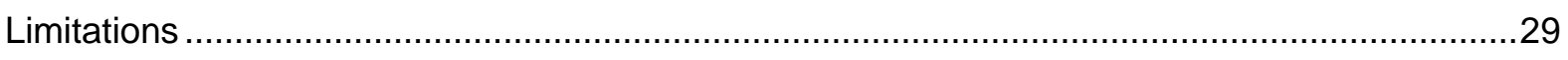

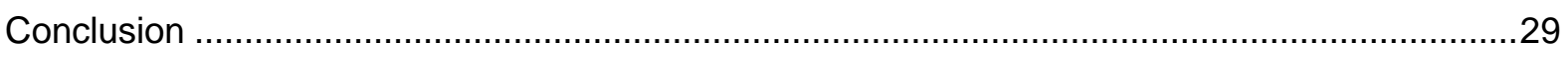

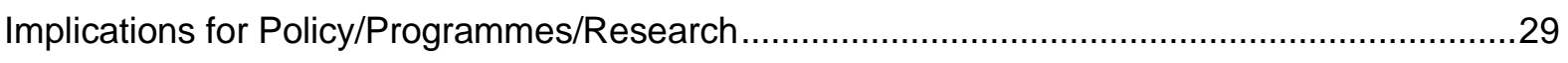

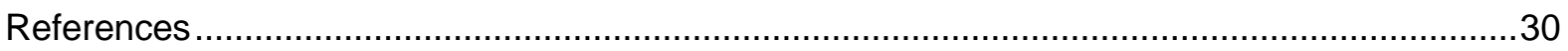




\section{List of Acronyms}

$\begin{array}{ll}\text { ACCAF } & \begin{array}{l}\text { Africa Coordinating Centre for the Abandonment of Female Genital Mutilation/ } \\ \text { Cutting }\end{array} \\ \text { CBO } & \text { Community-Based Organisation } \\ \text { FGD } & \text { Community Health Volunteer } \\ \text { FGM/C } & \text { Focus Group Discussion } \\ \text { GBV } & \text { Female Genital Mutilation/Cutting } \\ \text { HMIS } & \text { Hender-Based Violence } \\ \text { IDI } & \text { In-Depth Interview } \\ \text { IEC } & \text { Information, Education, and Communication } \\ \text { KII } & \text { Key Informant Interview } \\ \text { NACOSTI } & \text { National Commission for Science, Technology and Innovation } \\ \text { NGO } & \text { Nongovernmental Organisation } \\ \text { PRICOR } & \text { Primary Health Care Operations Research Project } \\ \text { SDG } & \text { Sustainable Development Goals } \\ \text { SDP } & \text { Service Delivery Points } \\ \text { STI } & \text { Sexually Transmitted Infection } \\ \text { UN } & \text { United Nations } \\ \text { UNFPA } & \text { United Nations Population Fund } \\ \text { UNICEF } & \text { United Nations Children Fund } \\ \text { WHO } & \text { World Health Organization }\end{array}$




\section{Acknowledgements}

We wish to thank colleagues at the Africa Coordinating Centre for the Abandonment of Female Genital Mutilation/Cutting (ACCAF): Prof. Jaldesa Guyo and Dr. Tammary Esho for their insights during the conception of this study. We also thank Drs Harriet Birungi, Jacinta Muteshi, Michelle Hindin and Caroline Kabiru of the Population Council who provided critical insights and expertise that greatly improved the design and implementation of the research. We thank Daniel Mwanga for his support during the quantitative data analysis, as well as Esther Lwanga for logistical support. We thank all the participants, healthcare providers, women living with FGM/C and research assistants for their participation and contribution to this important study. To the national government and county government of West Pokot we say a big thank you for your support and for providing a good environment for successful execution of this study. 


\section{Executive Summary}

\section{Background}

Female genital mutilation/cutting $(\mathrm{FGM} / \mathrm{C})$ is a cultural practice associated with health consequences, women/girls rights abuse, and violation. The health sector is well positioned to respond to $\mathrm{FGM} / \mathrm{C}$ through prevention and care interventions for women and girls living with complications. The Kenyan health sector-led FGM/C-related interventions are anchored in the legal and policy instruments and guidelines adapted from global/regional frameworks, as well as interventional tools approved by the World Health Organization (WHO). Despite the existence of the instruments, guidelines, and tools that should direct a robust health system's response to $\mathrm{FGM} / \mathrm{C}$, the practice persists while the quality-of-care services for the women and girls with FGM/C-related complications has not been ascertained. Evidence on whether the health sector implements relevant FGM/C-related legal and policy frameworks to address the practice and its related impacts is also lacking. To address these gaps, we conducted a diagnostic assessment of the health sector's response to FGM/C management and prevention, with a view to identifying possible solutions to strengthen it to contribute to the abandonment of FGM/C. We selected West Pokot County, which borders Uganda, as the primary study site because of the high prevalence of FGM/C among the Pokot, who predominantly practise infibulation-a practice associated with an increased risk of health complications. West Pokot is also a target county for the UNFPA-UNICEF Joint Programme on Female Genital Mutilation/Cutting: Accelerating Change.

\section{Methods}

We conducted a mixed-method study involving qualitative and quantitative data collection at national, county, and health-facility levels. We conducted (1) key informant interviews (KIIs) with FGM/C policy actors at national and county levels; (2) focus group discussions (FGDs) with service providers; (3) in-depth interviews (IDIs) with service providers; (4) health facility assessments; (5) observations of client-provider interactions; (6) client exit interviews; and (7) service data abstraction. The participants included national and county actors involved in policy formulation from the government (relevant ministries, departments, and agencies), health-related development partners, nongovernmental organisations (NGOs), health professional regulatory organisations and associations, and training institutions. We also interviewed doctors, nurses/midwives, and clinical officers working in West Pokot health facility service delivery points, as well as girls (14-17 years) and women (18 years and older) seeking care for FGM/C-related complications. Qualitative data were transcribed and analysed using a framework method template, while quantitative data were descriptively analysed. Ethical approvals were granted by the AMREF Ethics and Research Committee and the Population Council Institutional Review Board. The administrative approvals were granted by the National Commission for Science, Technology and Innovation (NACOSTI), the West Pokot County Commissioner, and the Director of Health Services in West Pokot.

\section{Results}

We conducted four FGDs, 23 IDIs, 34 KIls, 360 exit interviews, 61 client-provider interactions, 30 health facility assessments, and service data abstraction from 10 facilities. We outline the key study findings below.

There were variations in awareness or knowledge of laws and policies that address FGM/Crelated prevention and management. Some national- and county-level actors identified various health sector-relevant laws addressing prevention and management of FGM/C. The laws included the Constitution of Kenya 2010, which guarantees fundamental rights; the Prohibition of FGM Act of 2011, which criminalises and prescribes fines/punishment for cutting; the Children Act of 2001, which prohibits FGM/C among those younger than 18 years; and the Protection against Domestic 
Violence Act of 2015 , which considers FGM/C a form of violence. The development and review of FGM/C-related laws were linked to the adoption of global or regional instruments and triggered by FGM/C-related health consequences, poor maternal indicators, social economic impacts (e.g., low education attainment or school dropouts), adoption of the Sustainable Development Goals, the need to address human rights violations, as well as a high FGM/C burden.

Most national actors highlighted various FGM/C-related policies relevant to the health sector including the National Adolescent Sexual and Reproductive Health Policy. At the county level, participants made reference to the national School Health Policy. These policies were noted to lack details on the prevention of medicalisation and the management of FGM/C-related complications. A lack of guidelines that addressed management and prevention of $\mathrm{FGM} / \mathrm{C}$ was also noted to lead to a generic approach to interventions just like other medical/surgical cases.

The service data abstraction and health facility assessments showed that there was limited or inconsistent documentation of FGM/C-related cases and complications in the service delivery points. For example, although participants noted that women and girls presented to health facilities with bleeding and infections related to FGM/C, there were no data supporting the information. Furthermore, data on those who sought care for FGM/C-related complications were lacking. The lack of data was attributed to the absence of a policy framework providing for the availability of FGM/C-related data-capture tools at the service points. Although data on reproductive health services were available, data on women and girls with $\mathrm{FGM} / \mathrm{C}$ and/or related complications who sought antenatal, postnatal, family planning, and youth-friendly services were lacking.

Although West Pokot County had adequate health infrastructural and human capacity to conduct preventive interventions for priority programmes, only minimal unstructured FGM/C prevention interventions were implemented. These included counselling of clients with $F G M / C$ on the practice, its attendant complications, and the need to protect daughters from cutting. Although the client interviews showed there were explanations (99\%) and instructions $(89 \%)$ for treatments to clients, most providers (84\%) did not explain the negative consequences of $\mathrm{FGM} / \mathrm{C}$ or discuss the need to stop practising FGM/C. Most providers did not identify or enquire about FGM/C status, its severity, and possible FGM/C-related effects, nor did they inform clients of findings from their physical examination.

The health sector leveraged on school health, community outreach, community volunteerled,, and vernacular radio shows to create FGM/C awareness. Facility-linked health talks on FGM/C by health providers were reported, but only $23 \%$ of health facilities shared information on or discussed FGM/C, while approximately $70 \%$ health facilities failed to educate or advise clients on FGM/C. Some community health volunteer-led FGM/C prevention and vernacular radio FGM/C messaging were implemented. Another approach involved motivating pregnant women and incentivising traditional birth attendants to address $\mathrm{FGM} / \mathrm{C}$ and poor birth outcomes. These interventions were, however, hampered by the lack of guidelines and protocols; information, education, and communication (IEC) resources; inadequate capacity of healthcare providers; and limited funding.

We found that women and girls presented with a wide range of complications including sexual and psychological complications. Women were reported to present with birth complications including tears on the external genitalia, and postpartum haemorrhage prompting episiotomies, and caesarean section. Long-term complications included fistulas, scars, and keloids, while psychological impacts included psychological trauma and stigmatisation. Women were noted to present with FGM/C-related sexual complications characterised by difficulty in penetration, painful intercourse, and lack of enjoyment. 
Although some clients received treatment in the first health facility they presented to, many women and girls were referred to higher-level facilities because providers lacked the capacity to address these complications. The referrals for women with FGM/C-related birth complications to higher-level facilities existed in $63 \%$ of facilities. The FGM/C-related referrals included birth complications (48\%), gynaecological $(32 \%)$ and immediate $(11 \%)$ complications.

Although women/girls were noted to present with FGM/C-related complications, there were no specific interventions prescribed in the guidelines and protocols to address them. Instead the complications were generally managed symptomatically. Noteworthy were the challenges performing de-infibulation to address FGM/C-related birth complications because of limited capacity resulting in many of these complications being managed through episiotomies and caesarean sections. We found no evidence of interventions implemented to mitigate sexual and psychological complications.

\section{Conclusion}

The Kenyan health-sector response to FGM/C prevention and management is anchored in legal and policy instruments adopted from global and regional frameworks. Although the instruments are well understood by policy actors at the national and county level, few healthcare providers appear to be aware of these instruments. This limited awareness has a negative impact on the quality of care received by women and girls and curtails the involvement of health system actors in prevention efforts. Further, the health system lacks procedures to document and capture data related to FGM/C cases or complications, which may limit programming and investments targeted to the prevention and management of the practice. These findings underscore the need for investments to strengthen the health sector's response to $\mathrm{FGM} / \mathrm{C}$ by developing appropriate FGM/C-related tools and guidelines that inform the prevention, management, and quality of care for women with $\mathrm{FGM} / \mathrm{C}$, including integration of interventions at all levels of the health sector.

\section{Implications for policy/programmes/research}

The study findings highlight several possible avenues for leveraging positive change:

- Stakeholders in different levels of the health system should be sensitised about laws and policies that address $\mathrm{FGM} / \mathrm{C}$ prevention and management.

- Tools to guide and support FGM/C-related prevention and management interventions should be developed.

- Healthcare providers should be adequately trained to respond to women and girls with FGM/Crelated complications including birth, sexual, and psychological factors.

- Systems to collect and document data on FGM/C in health facilities should be developed for use in policy, programming, and investment decision-making.

- The referral system for FGM/C-related complications should be strengthened.

- The health system should be adequately integrated and financed to respond to prevention and management of $\mathrm{FGM} / \mathrm{C}$.

- A cost-utility analysis to examine the financial implication of integration of FGM/C interventions into the health services is needed. 


\section{Introduction}

The practice of female genital mutilation/cutting (FGM/C) undermines women's and girls' rights, health, and full realisation of their potential. The practice involves partial or total removal of the female external genitalia or other injuries to the female genital organs for nonmedical reasons (WHO 2008, 2016). The World Health Organisation (WHO) categorises the practice into four types: type I-partial or total removal of the clitoris and/or the prepuce (clitoridectomy); type II - partial or total removal of the clitoris and the labia minora, with or without excision of the labia majora (excision); type III-narrowing of the vaginal orifice with creation of a covering seal by cutting and appositioning the labia minora and/or the labia majora, with or without excision of the clitoris (infibulation); and type IV—all other harmful procedures to the female genitalia for nonmedical purposes, including pricking, piercing, incising, scraping and cauterisation (WHO 2016).

Despite the practice of $\mathrm{FGM} / \mathrm{C}$ being culturally entrenched, it also spreads with migration of the practising communities. Globally, over 200 million women and girls are cut and living with FGM/Crelated consequences (UNICEF 2016), while 3.6 million girls are at risk of undergoing cutting each year (UNICEF 2016). The greatest magnitude and the risk for FGM/C are disproportionally borne across different ethnic groups in 28 African countries (mainly in East, North East, and West Africa), pockets in Asia, the Middle East, Latin America, and in North America, Europe, Australia, and New Zealand among migrant practising populations (UNICEF 2016; Yoder, Wang, and Johansen 2013). In Kenya, FGM/C is traditionally practised by all but five ethnic groups. In 2014, the national prevalence among women and girls aged $15-49$ years was $21 \%$, spanning from a high of $94 \%$ in the North Eastern counties to a low of $1 \%$ in Western Kenyan, depending on the ethnic and geographical determinants relevant to the practice (KDHS 2014). Further, there is evidence of increasing medicalisation (performance of FGM/C by health professionals) and in 2014, about one in five (19.7\%) cut girls had been cut by a health professional (KDHS 2014), with the prevalence of medicalisation varying by ethnicity, geographic location, and education among other factors (KDHS 2014).

There are no health benefits associated with FGM/C; instead it has undesirable consequences on health (physical, psychological, sexual) and social well-being (Chibber, El-Saleh, and El Harmi 2011; Kimani, Muteshi, and Njue 2016; Vloeberghs et al. 2012; WHO 2006). High rates of maternal and infant morbidity and mortality are common among communities that practise $\mathrm{FGM} / \mathrm{C}$ (WHO 2006). The health harms associated with FGM/C can be immediate, short- and/or long-term (Berg et al. 2016; Kaplan et al. 2011; WHO 2006). Complications include severe bleeding, urine and menstrual retention, cysts, infections (including genital, reproductive, and urinary tract infections, and HIV), painful intercourse, and even death (Berg and Underland 2013; Bjälkander et al. 2012; Kimani, Muteshi, and Njue 2016; Njue and Askew 2004). Psychologically, women and girls who have undergone FGM/C have been reported to struggle with anxiety, depression, post-traumatic stress disorder, and low self-esteem (Behrendt and Moritz 2005; Whitehorn, Ayonrinde, and Maingay 2002). The majority of women and girls living with $\mathrm{FGM} / \mathrm{C}$ suffer complications that require medical interventions to correct or mitigate the health risks.

The health sector is strategically positioned to prevent $\mathrm{FGM} / \mathrm{C}$ and manage related complications. The health sector-led FGM/C prevention should include: i) communicating risks and health consequences of the practice; and ii) supporting implementation of policies for the abandonment of FGM/C by communities and families including addressing medicalised $F G M / C$, and fulfilling the legal requirements for reporting cases of $\mathrm{FGM} / \mathrm{C}$ to the law enforcement authorities. Similarly, the health sector should respond to women and girls who are living with FGM/C-related complications, spanning from immediate to long-term including psychological and sexual consequences (Kimani, Muteshi, and Njue 2016, Kimani et al. 2018). 
Globally, there is increasing support for and commitment to tackling FGM/C through the development of legal and policy frameworks addressing the prevention and management of FGM/C. To date, 26 African and Middle Eastern nations as well as 33 countries with FGM/Cpractising migrant populations have adopted laws criminalising the practice (UNICEF, 2016). Additionally, to operationalise the health sector-led management and prevention of FGM/C, WHO developed supporting guidelines and tools in 2016 and 2018 (WHO 2016, 2018), respectively, for countries to adapt and adopt.

To address the prevention and management of FGM/C in Kenya, various legal instruments have been developed and adopted. These are the Prohibition of Female Genital Mutilation Act of 2011 (National Council for Law Reporting 2011); Children's Act of 2001 (HMSO 2004); Penal Code Chapter 63 (Republic of Kenya 2012b); and Protection Against Domestic Violence Act of 2015 (Republic of Kenya 2015). These legal instruments also prohibit the medicalisation of $F G M / C$, which includes re-infibulation (re-suturing of the external genitalia to the infibulated state) at any point in time in a woman's life following delivery, de-infibulation, and related gynaecological interventions. The Prohibition of Female Genital Mutilation Act spells out jail terms and penalties for the perpetrators and any parties who aid or abet the practice. The Act also requires anyone who is aware of the conduct of $\mathrm{FGM} / \mathrm{C}$ on a woman or girl to report such incidents to law enforcement authorities. By implication, health providers are legally obliged to report fresh cases of FGM/C encountered in their course of duty, however there is weakness in the implementation of these provisions

To operationalise the laws, the government has developed policies such as the Adolescent Sexual and Reproductive Health Policy of 2015 (MOH 2015), and the National School Health Policy of 2009 revised in 2018 (Republic of Kenya 2018). Furthermore, plans of action and strategies have been developed in line with sector-specific policies to support the prevention and management of $\mathrm{FGM} / \mathrm{C}$ in various settings.

The laws, diverse policies, plans of action, and implementation strategies, as well as a reference manual for the management and prevention of FGM/C (Manual, 2007) should provide a perfect environment for the health sector to respond significantly with regard to FGM/C abandonment. However, the implementation of these comprehensive, well-intended documents has not been evaluated, with indications that the health sector may not have been able to implement them.

\section{Theoretical underpinnings}

To better understand the Kenyan health system's response to FGM/C, we conducted a diagnostic assessment with the aim of identifying possible solutions for strengthening it. The study was anchored on Miller and colleagues' situation analysis framework (Miller et al. 1997), and modelled around the systems thinking of the Primary Health Care Operations Research Project (PRICOR) (Center for Human Services 1998), Frerich's Rapid Survey Methodology (Frerichs 1989; Frerichs and Khin Tar Tar 1989) as well as the quality of care framework as described by Bruce (Bruce 1990). In addition, the study was anchored on the WHO health-systems framework (WHO 2007). The framework describes health systems in terms of six building blocks, namely: service delivery; health workforce; health information systems; access to essential medicines, vaccines, and technologies; financing; and leadership and governance. The approach helped assess the quality of care for the management of FGM/C-related complications by delving into current policy frameworks, programme standards, readiness of service delivery staff, and facilities, actual quality of service received, and impact of services on client satisfaction across service delivery points (SDPs) (Miller et al. 1997). 


\section{Objectives}

\section{Broad objective}

To assess the health sector's response to FGM/C management and prevention, with a view to identifying possible solutions for strengthening the sector's contribution to the abandonment of $\mathrm{FGM} / \mathrm{C}$ in Kenya.

\section{Specific objectives}

1. To examine how the healthcare sector supports prevention of $F G M / C$ in line with country laws and policies;

2. To determine the role of the healthcare sector in the management of FGM/C-related complications and the quality of care offered to clients; and

3. To identify possible solutions for strengthening the healthcare sector towards management and prevention of $\mathrm{FGM} / \mathrm{C}$.

\section{Research questions}

This study sought to address the following key research questions:

1. How is the health sector responding to existing FGM/C-related laws and policies?

2. What role is the healthcare sector playing in the prevention of FGM/C?

3. What are contextual factors supporting or inhibiting the health sector's response to $\mathrm{FGM} / \mathrm{C}$ ?

4. What are the availability, content, and quality of FGM/C-related service provisions?

5. How is the health sector catering to the needs of women and girls who have undergone $\mathrm{FGM} / \mathrm{C}$ ?

\section{Methods}

\section{Study design}

We conducted a mixed-method study involving qualitative and quantitative data collection at national, county (West Pokot County), and health-facility levels in Kenya. We conducted (1) key informant interviews (KIIs) with FGM/C policy actors at the national and county level; (2) focus group discussions (FGDs) with service providers and women with FGM/C; (3) in-depth interviews (IDIs) with service providers; (4) health facility assessments; (5) observations of client-provider interactions; (6) client exit interviews; and (7) service data abstraction (Table 1).

The policy/standards relevant to the prevention and management of FGM/C-related complications were appraised through data collected from health facility assessments. Information obtained from the health facility assessment helped determine facility readiness to provide services to survivors of FGM/C-related complications. Staff readiness to provide FGM/C- related services were assessed through FGDs and IDIs with different cadres of health providers working at service delivery points that encountered women/girls who had experienced FGM/C-related complications. Information on the content and quality of FGM/C-related service delivery were obtained through observations of client-provider interactions, client exit interviews following client-provider interactions, and a review of FGM/C-related data in facility health records (service data abstraction). Data were analysed and information triangulated to create a valid picture of the health sector response to $\mathrm{FGM} / \mathrm{C}$. 
Table 1. A summary of data-gathering activities and their corresponding sample size

\begin{tabular}{|c|c|c|c|c|}
\hline $\mathbf{S} / \mathbf{N}$ & $\begin{array}{l}\text { Data- } \\
\text { gathering } \\
\text { activity }\end{array}$ & Study population & Sample size & Study location \\
\hline 1 & $\begin{array}{l}\text { Key } \\
\text { informant } \\
\text { interview }\end{array}$ & $\begin{array}{l}\text { Representatives from the government } \\
\text { (relevant ministries and parastatals), private } \\
\text { organisations, NGOs, health development } \\
\text { partners, health professional associations, } \\
\text { health professional regulatory organisations, } \\
\text { and training institutions }\end{array}$ & 34 & $\begin{array}{l}\text { National and } \\
\text { county levels }\end{array}$ \\
\hline 2 & $\begin{array}{l}\text { Focus group } \\
\text { discussions }\end{array}$ & $\begin{array}{l}\text { Healthcare workers (nurses/midwives), } \\
\text { women with FGM-related complications }\end{array}$ & $\begin{array}{l}32 \text { (Nurse- } \\
\text { midwives-3 groups } \\
\text { of } 8 \text { participants, } \\
\text { Women with FGM-1 } \\
\text { group of } 8 \\
\text { participants) }\end{array}$ & County level \\
\hline 3 & $\begin{array}{l}\text { In-depth } \\
\text { interviews }\end{array}$ & $\begin{array}{l}\text { Healthcare workers (doctors, } \\
\text { nurses/midwives, clinical officers) working at } \\
\text { selected service delivery points }\end{array}$ & $\begin{array}{l}23 \text { (doctors-6, } \\
\text { clinical officers-5, } \\
\text { Nurse-Midwives-12) }\end{array}$ & $\begin{array}{l}\text { County-level } \\
\text { health facilities }\end{array}$ \\
\hline 4 & $\begin{array}{l}\text { Health facility } \\
\text { assessment }\end{array}$ & $\begin{array}{l}\text { Health facility administrators of tertiary, } \\
\text { secondary, primary, and private service } \\
\text { delivery points }\end{array}$ & 30 & $\begin{array}{l}\text { County-level } \\
\text { health facilities }\end{array}$ \\
\hline 5 & $\begin{array}{l}\text { Observations } \\
\text { of client- } \\
\text { provider } \\
\text { interactions }\end{array}$ & $\begin{array}{l}\text { Healthcare providers and women with } \\
\text { FGM/C-seeking reproductive health services }\end{array}$ & 61 & $\begin{array}{l}\text { County-level } \\
\text { health facilities }\end{array}$ \\
\hline 6 & $\begin{array}{l}\text { client exit } \\
\text { interviews }\end{array}$ & $\begin{array}{l}\text { Women with FGM/C-seeking reproductive } \\
\text { health services }\end{array}$ & 360 & $\begin{array}{l}\text { County-level } \\
\text { health facilities }\end{array}$ \\
\hline 7 & $\begin{array}{l}\text { Service data } \\
\text { abstraction }\end{array}$ & $\begin{array}{l}\text { Health facility administers, healthcare } \\
\text { providers }\end{array}$ & 10 & $\begin{array}{l}\text { County-level } \\
\text { health facilities }\end{array}$ \\
\hline
\end{tabular}

\section{Study sites}

Interviews with legal and policy actors at the national level were conducted in Nairobi. All other data were collected in West Pokot county. The county is in the Rift Valley bordering the Republic of Uganda and covering an area of $9,169.39 \mathrm{KM}^{2}$. In 2015 , the county had an estimated population of about 600,000 people (49.7\% male) (KDHS 2014). The county had 126 health facilities categorised into 87 public, three nongovernmental, 20 faith-based, and 16 private operated health facilities, respectively (KMHFL 2017). In 2013, the provider to population ratios were 67 nurses, five doctors, and 23 clinical officers per 100,000 people (Mapping Report 2013). Most women in the county deliver at home assisted by traditional birth attendants, with only $25.8 \%$ of births delivered at a health facility (KDHS 2014). The county has high maternal and infant mortality rates.

The county is inhabited mainly by the Pokot people and other dominant Kalenjin communities. The Pokot community practises type III FGM/C with a high prevalence of $94 \%$. There is no documented evidence of healthcare providers being involved in cutting girls in West Pokot. Girls are cut at an age of 12-15 years as a rite of passage to adulthood by traditional practitioners, and the shifts associated with FGM/C observed in other communities (Kimani and Kabiru 2018) have not been reported. Furthermore, cross-border dynamics associated with FGM/C are rife because the Pokot community members are also found in Uganda and share a porous border. Programmatically, West Pokot has been a target county for the UNFPA-UNICEF Joint Programme on FGM/C.

\section{Participants}

Study participants included national-level stakeholders/actors from Nairobi and West Pokot county stakeholders/actors involved in FGM/C-related law/policy processes such as representatives from 
government (relevant ministries, departments, and agencies), health-related development partners, non-governmental organisations (NGOs), health professional regulatory organisations, health professional associations, training institutions, and community-based organisations. We also recruited healthcare providers including doctors, nurses/midwives, and clinical officers working in service delivery points who encountered and/or dealt with women/girls with FGM/Crelated complications (antenatal, postnatal, family planning, youth-friendly, delivery and newborn services; and accident and emergency departments in both public and private tertiary, secondary, primary, and private/faith based facilities). We also recruited girls (14-17 years) and women (18 years and above) with FGM/C-related complications.

\section{Sampling and sample size}

Participants for the policy-relevant interviews were purposively selected to include those who had been involved in the policy processes of FGM/C-related laws, policies, and guidelines. Health providers were also purposively recruited to include a mix of providers who worked in service points that encounter girls and women who had undergone $\mathrm{FGM} / \mathrm{C}$ and to represent a mix of providers working in tertiary, secondary, primary, and private health facilities across West Pokot county.

The sample size for FGDs was informed by thematic saturation of data, and the size for those who participated in IDIs and KIls was informed by representation across sectors and actors, thematic saturation, geographic locations, and categories of the health facilities. A total of four FGDs, 23 IDIs, and $34 \mathrm{KIls}$ were conducted. We interviewed five clinical officers, six medical officers, and 11 nurses or midwives. Table 2 summarises the demographic characteristics of participants in IDIs and KIIs. The majority (65\%) were males and of Pokot ethnicity $(49 \%)$. About a third $(32 \%)$ of these participants were aged 21-30 years, 25\% were aged $31-40$ years and $40 \%$ were older than 40 years. Fifty-three percent of the healthcare providers had worked at the health facility for over six years while $47 \%$ reported that they had worked in the facility for less than six years.

Table 2. Demographic characteristics of participants in the in-depth interviews (IDIs) and key informant interviews (KIls)

\begin{tabular}{|lcccc|}
\hline Characteristics & (n) & $\begin{array}{c}\text { IDIs (N=23) } \\
\text { Percent }\end{array}$ & (n) & $\begin{array}{c}\text { KIIs (N=34) } \\
\text { Percent }\end{array}$ \\
\hline Gender & & & & \\
$\quad$ Male & 14 & 60.9 & 23 & 67.7 \\
$\quad$ Female & 9 & 39.1 & 11 & 32.3 \\
Ethnicity & & & & \\
$\quad$ Pokot & 9 & 39.1 & 19 & 55.9 \\
$\quad$ Other ethnicity & 8 & 34.8 & 12 & 35.3 \\
$\quad$ Other Kalenjin group & 4 & 17.4 & 1 & 2.9 \\
$\quad$ Missing & 2 & 8.7 & 2 & 5.9 \\
Age (years) & & & & \\
$\quad 21-30$ & 14 & 60.9 & 4 & 11.7 \\
$\quad 31-40$ & 2 & 8.7 & 12 & 35.3 \\
$\quad 41$ or older & 6 & 26.1 & 17 & 50.0 \\
$\quad$ Missing & 1 & 4.3 & 1 & 2.9 \\
Years at the facility/organisation & & & & \\
$\quad$ O-5 years & 17 & 73.9 & 10 & 29.4 \\
$\quad$ + years & 6 & 26.1 & 24 & 70.6 \\
Section/department (IDI only) & & & & \\
$\quad$ Clinical assessment room & 1 & 4.3 & - & - \\
$\quad$ Maternity & 8 & 34.8 & - & - \\
$\quad$ Obstetric & 3 & 13.0 & - & - \\
$\quad$ OPD & 4 & 17.4 & - & - \\
$\quad$ Theatre & 4 & 17.4 & - & - \\
$\quad$ Other & 4 & 17.4 & - & - \\
Cadre of the officer (IDI only) & & & - & - \\
\hline
\end{tabular}




\begin{tabular}{|c|c|c|c|c|}
\hline \multirow[t]{2}{*}{ Characteristics } & \multicolumn{2}{|c|}{ IDls ( $\mathbf{N = 2 3 )}$} & \multicolumn{2}{|c|}{ KIIs (N=34) } \\
\hline & (n) & Percent & (n) & Percent \\
\hline Clinical officer & 5 & 21.7 & - & - \\
\hline Medical officer & 6 & 26.1 & - & - \\
\hline Nurse/midwife & 12 & 52.1 & - & - \\
\hline \multicolumn{5}{|l|}{ Organisation represented (KII only) } \\
\hline Government & - & - & 18 & 52.9 \\
\hline Health development partners & - & - & 3 & 8.8 \\
\hline Health professional associations & - & - & 4 & 11.8 \\
\hline NGOs players in FGM/C & - & - & 5 & 14.7 \\
\hline Missing & - & - & 4 & 11.8 \\
\hline
\end{tabular}

A multistage sampling was used to sample respondents and facilities for quantitative data. We clustered the facilities into different categories (tertiary, secondary, primary, and private/faithbased) using a list of health facilities obtained from the county health office. We then sampled all facilities in sub-counties with a high prevalence of FGM/C. Clients were recruited for the exit interviews and observations of client-provider interactions as they sought services from health facilities in West Pokot. Eligible girls (14-17 years) and women (18 years and older) with FGM/Crelated complications were identified, recruited and consent obtained to participate in the exit interviews and client-provider interaction observations The clients who participated in the exit interviews and client-provider interaction were conveniently sampled after they met the inclusion criteria. A total of 360 exit interviews and 61 client-provider interactions were conducted. Table 3 summarises the demographic characteristics of the exit interview respondents. Thirty-nine percent were aged $15-19$ years while $38 \%$ were aged between 20 and 30 years. A majority (53\%) were in a monogamous marriage. About half $(52 \%)$ had $1-3$ children. A third of the respondents $(33 \%)$ had never attended formal schooling while $48 \%$ had primary-level education. About a quarter (26\%) reported having no income at all, 17\% earned less than 3,000 Kenyan Shillings ( 30 US dollars), 16\% between 3,000-5,000 Kenyan Shillings, 13\% between 10,000-20,000 Kenyan Shillings while $7 \%$ earned more than 20,000 Kenyan Shillings. Most $(76 \%)$ of the interviewed participants reported that they had undergone FGM/C when aged 11-15 years, with the procedure mainly (95\%) performed by traditional circumcisers.

Table 3. Demographic characteristics of participants during exit interviews $(n=360)$

\begin{tabular}{|c|c|c|c|c|c|c|c|c|}
\hline \multirow{3}{*}{ Characteristics } & \multicolumn{8}{|c|}{ FACILITY LEVEL } \\
\hline & \multicolumn{2}{|c|}{$\begin{array}{l}\text { Primary } \\
\mathrm{N}=220\end{array}$} & \multicolumn{2}{|c|}{$\begin{array}{l}\text { Secondary } \\
N=98\end{array}$} & \multicolumn{2}{|c|}{$\begin{array}{l}\text { Tertiary } \\
\mathrm{N}=42\end{array}$} & \multicolumn{2}{|c|}{$\begin{array}{l}\text { Total } \\
\mathrm{N}=360\end{array}$} \\
\hline & $\mathrm{n}$ & $\%$ & $\mathrm{~N}$ & $\%$ & $\mathrm{n}$ & $\%$ & $\mathrm{n}$ & $\%$ \\
\hline \multicolumn{9}{|l|}{ Age } \\
\hline$<15$ years & 3 & 1.4 & 1 & 1 & 0 & 0 & 4 & 1.1 \\
\hline $15-19$ years & 95 & 43.2 & 33 & 33.7 & 12 & 28.6 & 140 & 38.9 \\
\hline 20-24 years & 37 & 16.8 & 21 & 21.4 & 10 & 23.8 & 68 & 18.9 \\
\hline $25-30$ years & 35 & 15.9 & 18 & 18.4 & 13 & 31 & 66 & 18.3 \\
\hline 30 years or older & 50 & 22.7 & 25 & 25.5 & 7 & 16.7 & 82 & 22.8 \\
\hline \multicolumn{9}{|l|}{ Marital status } \\
\hline Married/monogamous & 100 & 45.5 & 61 & 62.2 & 31 & 73.8 & 192 & 53.3 \\
\hline Married/polygamous & 83 & 37.7 & 29 & 29.6 & 9 & 21.4 & 121 & 33.6 \\
\hline Single, never married & 30 & 13.6 & 5 & 5.1 & 2 & 4.8 & 37 & 10.3 \\
\hline Divorced/separated/widowed & 2 & 0.9 & 0 & 0 & 0 & 0 & 2 & 0.6 \\
\hline Missing & 5 & 2.3 & 3 & 3.1 & 0 & 0 & 8 & 2.2 \\
\hline Number of living children & & & & & & & & \\
\hline
\end{tabular}




\begin{tabular}{|c|c|c|c|c|c|c|c|c|}
\hline \multirow{3}{*}{ Characteristics } & \multicolumn{8}{|c|}{ FACILITY LEVEL } \\
\hline & \multicolumn{2}{|c|}{$\begin{array}{l}\text { Primary } \\
\mathrm{N}=220\end{array}$} & \multicolumn{2}{|c|}{$\begin{array}{l}\text { Secondary } \\
N=98\end{array}$} & \multicolumn{2}{|c|}{$\begin{array}{l}\text { Tertiary } \\
\mathrm{N}=42\end{array}$} & \multicolumn{2}{|c|}{$\begin{array}{l}\text { Total } \\
\mathrm{N}=360\end{array}$} \\
\hline & $\mathrm{n}$ & $\%$ & $\mathrm{~N}$ & $\%$ & $\mathrm{n}$ & $\%$ & $\mathrm{n}$ & $\%$ \\
\hline None & 30 & 13.6 & 8 & 8.2 & 3 & 7.1 & 41 & 11.4 \\
\hline $1-3$ children & 108 & 49.1 & 50 & 51 & 29 & 69 & 187 & 51.9 \\
\hline $4-7$ children & 52 & 23.6 & 23 & 23.5 & 6 & 14.3 & 81 & 22.5 \\
\hline 7 or more children & 26 & 11.8 & 11 & 11.2 & 3 & 7.1 & 40 & 11.1 \\
\hline Missing & 4 & 1.8 & 6 & 6.1 & 1 & 2.4 & 11 & 3.1 \\
\hline \multicolumn{9}{|l|}{ Education level } \\
\hline Did not attend formal school & 73 & 33.2 & 35 & 35.7 & 11 & 26.2 & 119 & 33.1 \\
\hline Primary & 109 & 49.5 & 48 & 49 & 14 & 33.3 & 171 & 47.5 \\
\hline Secondary & 33 & 15 & 8 & 8.2 & 12 & 28.6 & 53 & 14.7 \\
\hline Tertiary & 3 & 1.4 & 6 & 6.1 & 5 & 11.9 & 14 & 3.9 \\
\hline Missing & 2 & 0.9 & 1 & 1 & 0 & 0 & 3 & 0.8 \\
\hline \multicolumn{9}{|l|}{ Monthly income (Kenyan Shillings) } \\
\hline None & 31 & 28.4 & 9 & 17 & 10 & 35.7 & 50 & 26.3 \\
\hline$<3000$ & 25 & 22.9 & 5 & 9.4 & 2 & 7.1 & 32 & 16.8 \\
\hline 3000 to $<5000$ & 20 & 18.3 & 9 & 17 & 1 & 3.6 & 30 & 15.8 \\
\hline 5000 to $<10000$ & 22 & 20.2 & 13 & 24.5 & 5 & 17.9 & 40 & 21.1 \\
\hline 10000 to $<20000$ & 8 & 7.3 & 9 & 17 & 7 & 25 & 24 & 12.6 \\
\hline 20000 or more & 3 & 2.8 & 8 & 15.1 & 3 & 10.7 & 14 & 7.4 \\
\hline Total & 109 & 100 & 53 & 100 & 28 & 100 & 190 & 100 \\
\hline Missing/don't know & 111 & 50.5 & 45 & 45.9 & 14 & 33.3 & 170 & 47.2 \\
\hline \multicolumn{9}{|l|}{ Age of undergoing FGM } \\
\hline $8-10$ years & 9 & 4 & 8 & 9 & 3 & 7 & 20 & 5.6 \\
\hline $11-15$ years & 169 & 77 & 75 & 77 & 30 & 71 & 274 & 76.1 \\
\hline $16-19$ years & 38 & 17 & 15 & 15 & 8 & 19 & 61 & 16.9 \\
\hline 20 years and above & 4 & 2 & 0 & 0 & 1 & 2 & 5 & 1.4 \\
\hline
\end{tabular}

The characteristics and distribution of facilities where client-provider interactions were observed are summarised in Table 4. The facilities were located in four sub-counties; Pokot Central (39.3\%), Pokot South (24.6\%), Pokot West (21.3\%), and Pokot North (14.8\%). The majority (92\%) of the observations were conducted in primary-level health facilities-dispensaries and health centres.

Table 4. Characteristics and distribution of health facilities in which client-provider interactions were observed $(n=61)$

\begin{tabular}{|lcc|}
\hline Characteristics & Frequency (n) & Percent (\%) \\
\hline Sub-county & & \\
$\quad$ Pokot West & $(13)$ & 21.3 \\
Pokot Central & $(24)$ & 39.3 \\
Pokot North & $(9)$ & 14.8 \\
Pokot South & $(15)$ & 24.6 \\
$\quad$ Total & $(61)$ & 100 \\
Level of facility & $(56)$ & \\
$\quad$ Primary (health centre and dispensary) & $(4)$ & 61.80 \\
Secondary (sub-county hospital and & $(1)$ & 6.56 \\
mission led facilities) & $(61)$ & 1.64 \\
Tertiary (county referral hospital) & & 100 \\
Total & & \\
\hline
\end{tabular}


A total of 30 facilities were identified and selected for the health facility assessments-3\% tertiary, $13 \%$ secondary, and $83 \%$ primary or faith-based facilities spread across the four sub-counties. Data abstractions were conducted in 10 facilities-one tertiary, two secondary, five primary, and two private facilities.

\section{Study instruments}

The KII guide focused on events that triggered agenda-setting on FGM/C, the input of different stakeholders in the implementation of health system $\mathrm{FGM} / \mathrm{C}$ policies, and the process relating to FGM/C management and prevention strategies emanating from the policy. The FGD guide focused on eliciting responses on healthcare providers' experience and training on $\mathrm{FGM} / \mathrm{C}$, knowledge of $\mathrm{FGM} / \mathrm{C}$ prevention/management standards, attitudes towards $\mathrm{FGM} / \mathrm{C}$ practise, and implementation of existing $\mathrm{FGM} / \mathrm{C}$ policies, as well as $\mathrm{FGM} / \mathrm{C}$ prevention/management practises including referral mechanisms and supervision. The guide for IDIs with healthcare providers addressed general attitudes and knowledge on FGM/C, management of $F G M / C$ complications, prevention of $\mathrm{FGM} / \mathrm{C}$, supervisory mechanisms, and documentation of $\mathrm{FGM} / \mathrm{C}$. The validity of the guides was ensured through an extensive literature review to identify necessary questions as well as feedback received during exploratory meetings with stakeholders and during training sessions with research assistants. The discussions/interviews commenced with general statements followed with specific questions to elicit answers to the various thematic components regarding the health-sector responses to prevention and management of FGM/C-related complications.

The health facility assessment and client-provider interactions checklists, client exit interviews questionnaire, and service data abstraction tool were adopted and modified from a handbook entitled "Assessing Integration Methodology." There was a handbook for measuring and assessing the integration of family planning and other reproductive health services (Rivero-Fuentes et al. 2008). The health facility assessment inventory was a 129-question tool comprising nine sections designed to garner information on facility operations; provision of services; availability of equipment and service commodities; availability of information, education, and communication materials and activities; supervision; availability of protocols and guidelines; referral system related to $\mathrm{FGM} / \mathrm{C}$; and staffing. The tool was interviewer-administered. The structured provider interaction was documented using a checklist. This helped document interactions between provider and client on services that included identification, management, and prevention of FGM/C.

The exit interview questionnaires included socio-demographic information, and personal FGM/C Information-for example, whether the client had undergone FGM/C, including at what age, reasons why the clients visited the health facility-as well as whether the health provider discussed with them about FGM/C-related complications. Furthermore, the questionnaire had components on follow-up care and referrals, satisfaction with services, costs, and accessibility of the health services. The client exit interview questionnaire was translated into Kiswahili and local West Pokot languages.

We conducted health facility data abstraction using a checklist. The checklist contained the following components: facility identification; information on service statistics, such as number of pregnant women attending ANC and number of pregnant women with FGM/C attending ANC. Other questions included: number of women/girls with FGM/C-related complications, number of women/girls who have undergone $\mathrm{FGM} / \mathrm{C}$ and received counselling, etc, as well as the number of women/girls with FGM/C who received antibiotics and painkillers. The tools were pretested and validated during research-assistant trainings and feedback incorporated accordingly. 


\section{Recruitment and interview procedures}

The county-level governance participants were recruited after an exploratory visit to the county prior to the commencement of the study. The principal investigator and co-investigators met with the key stakeholders/actors to understand the county, the health system, and whether FGM/C was an important issue. During these meetings, the investigators explained the study objectives and sought a list of people/stakeholders who should be interviewed and participate in the study. The county and national governance stakeholders were contacted by phone or letter to inform them about the study and request their permission for the interview. Health providers were approached after obtaining permission to interview them from the Director of Health Services.

We obtained written or verbal informed consent from all participants. For the KIls, IDIs, and FGDs, we also obtained permission to audio record the interview or discussions. Participants were assured that all information provided would be treated with confidentiality and all the discussions and interviews were always conducted in private spaces that were convenient to the participants. The demographic characteristics for FGD participants were recorded on a self-completed participant record form. Except for the FGD with women living with FGM/C and the exit interviews which were conducted in the local dialect, all other FGDs, IDIs and KIls conducted in West Pokot were done in English by trained, locally recruited research assistants. The KIls conducted with national-level stakeholders were conducted in English by the study investigators. The discussion or interview started with general statements followed by specific questions as the participant got comfortable. The interviews lasted for about 45 minutes while FGDs lasted one and a half hours. The discussions were conducted by a moderator and a recorder in a quiet and private space with no interruptions. During the FGDs, the participants were seated in a circle, with sessions commencing with introductions, after which informed consent was obtained from each FGD member. The moderator commenced the discussion by presenting questions on general FGM/C issues, then delving into specific questions. The discussions were concluded by allowing contributions from every member until consensus was reached.

\section{Data analysis}

Quantitative data were coded and entered into Epi-data 3.1 on password-protected computers by trained data clerks and exported to STATA version 14.2 for data-quality assurance and cleaning. Cleaned data were then analysed using STATA version 14.2. Univariate and bivariate analyses were used to summarise the data with mean as a measure of central tendency and standard deviation as a measure of spread for continuous variables. Frequencies and proportions were reported for categorical variables. Some continuous variables were also categorised and presented as proportions. The data summaries are presented in the tables and graphs.

Digital audio recordings for the group discussions/interviews were subjected to a multi-stage transcription process to ensure data quality. First, recordings were transcribed verbatim by experienced transcribers. Second, the anonymised transcripts were independently reviewed, checking the transcripts against the original audio recordings for accuracy, spelling, and content. Any differences detected between the two formats were identified, discussed, and resolved. The finalised versions were then subjected to qualitative analyses.

The framework method for qualitative content analyses was adopted for this study (Ritchie et al. 2013) The framework method is appropriate for thematic analysis of textual data, particularly interview transcripts, where it is important to compare data by themes across many cases (Gale et al. 2013). This approach combines deductive and inductive analyses of textual data with the flexibility to adapt emerging data and produce a coding framework or "template." The themes/codes were selected through a combined approach: deductively based on previous 
literature and the specifics of the research question from the interview guides, as well as inductively generated from the obtained data in the transcripts, followed by their refinement.

Several team meetings between the investigators and qualitative research analysts were conducted to train the team members for a collaborative analysis and interpretation. The investigators and two research analysts developed a thematic coding framework through analysis of the study instruments and reading of the transcripts to reconcile and gain insights on emerging issues. The team reviewed the framework and definitions of each theme or code for consistency and understanding before commencement of coding using NVivo $11 \AA$. Data were first coded with descriptive labels, then categorised into "code families" based on identified patterns. Each analyst coded two transcripts to check the effectiveness of the coding framework that was used for the team discussion. The team then refined the final coding framework that was used in the subsequent analyses. The analysts were then assigned the remaining transcripts. The emerging themes during coding were addressed in regular weekly meetings until the process was complete. To ensure the methodological rigour and trustworthiness of the study data, and in addition to the use of researcher triangulation (using two data analysts) and method triangulation (using three different interview types [IDIs, KIls, and FGDs]), inter-rater coding reliability was assessed by having analysts coding a random sample of two transcripts coded by another analyst. Differences in coding were compared, discussed, and integrated by consensus. The data generated from the different methods were triangulated to form the narrative of this report.

\section{Ethical considerations}

Ethical approval for the study was granted by the Population Council's Institutional Review Board (Ref: 830; dated October 16, 2017) and AMREF Health Africa Ethics and Scientific Review Committee (Ref: AMREF-ESRC P463/2018; dated July 3, 2018). In addition, permission to carry out the study was granted by the National Commission for Science, Technology and Innovation (Ref: NACOSTI/P/18/79790/24356; dated August 18, 2018), the West Pokot County Commissioner and the County Director of Health Services. Study participants aged 18 years and older granted informed consent, while assent was obtained for participants younger than 18 years and consent granted by parent/guardian or husband or male partner. Participants were informed of and taken through the study protocol including the measures to ensure confidentiality of the information shared and their rights to withdraw from the study at any time. Interviews and discussions were audio recorded with permission from the participants.

\section{Results}

The findings from different data collection approaches are integrated, presented, and discussed through the lens of the WHO health systems framework, which entails six building blocks: leadership and governance; health information systems; financing; health workforce; service delivery; and availability of essential medicines, vaccines and technologies.

\section{Leadership and governance}

Leadership and governance entails laws and policy frameworks, coalition-building, regulation, and attention to system design and accountability. The establishment of laws and policies addressing $\mathrm{FGM} / \mathrm{C}$ means that the practice has become an important agenda item for discussion at the policy decision-making-level. In addition, since FGM/C abandonment require multi-sectoral collaboration, crosstalk, networking, and community strategies are important.

\section{Knowledge about laws and policies regarding FGM/C}

Most national-level stakeholders were aware of the various laws and policies that addressed FGM/C. The laws identified were the Children's Act of 2001, Prohibition of FGM Act of 2011, and Prohibition of Domestic Violence Act of 2015. Policies that were noted to address FGM/C included 
the National Adolescent Sexual and Reproductive Health Policy and the National School Health Policy. Participants also highlighted the Constitution of Kenya that was noted to recognise women's and girls' sexual and reproductive health rights and protects citizens from violence, with FGM/C being recognised as a form of violence. In describing the laws and policies, participants noted that the Prohibition of FGM Act criminalised FGM/C by defining the offence, and prescribing punishments for violators and those abetting $\mathrm{FGM} / \mathrm{C}$, and for those found with tools for performing the procedure, including medicalisation:

"Overall, we have the Constitution of Kenya, which protects and guarantees every one of their rights against violence in FGM, FGM being one of them. Then at the Ministry, we have the Kenya health, gender, and equality policy, although in draft form. Kenya health, gender, and equality policy, it's still a draft, where FGM is highlighted strongly, it's a violation to women and girls."

Representative of the National Ministry of Health, Nairobi

"The Prohibition of FGM Act is very critical for FGM/C prevention as it outlaws FGM/C from being done in a health facility and by health providers."

Representative of the Kenya Medical Practitioners and Dentists Council, Nairobi

As illustrated in the following quote, some participants noted that the development of the Prohibition of FGM Act and the Prohibition of Domestic Violence Act was necessitated by weaknesses identified during the implementation of the Children's Act of 2001.

"The Children's Act was the earliest to address FGM, but in most cases, community members used to wait until children were [older than] 18, then they would cut them."

Representative of a national NGO on women's rights

Some national-level participants narrated the history around the development and implementation of the laws and policies responding to $\mathrm{FGM} / \mathrm{C}$. As illustrated in the following quotation, some participants noted that several factors such as increasing awareness of the harmful health and social consequences of FGM/C had triggered the development of these laws and policies.

"There were a lot of publications, especially by WHO on the harmful health consequences associated with FGM. I remember in one of the documentaries that was presented at the International Conference on Population and Development in 1994, people were shown what doctors were encountering following FGM on girls. That triggered a movement within the international community; UNICEF, UNFPA came together and intensified efforts to address FGM-related health consequences. And this is where now the UN declarations come in and joint statements and that's why again, at this time, people felt like ...we focused so much on the health consequences."

International NGO representative, Nairobi

"The country realised that FGM was contributing negatively to so many issues around women empowerment including girls not reaching their full potential. This was contributing highly to girls not being empowered to be what they would want to become, and also was leading to very high maternal deaths, and contributing to high expenditure in the area of health management. We cannot realise the vision 2030 for Kenya or the SDGs [Sustainable Development Goals] if you don't deal with this FGM issue. So, the country had to really give FGM/C a priority. And that's why it had to have the law in place and also have a board in place to coordinate."

Anti-FGM Board representative, Nairobi

Although county actors, more so those who worked in administration and the social sector, were knowledgeable of laws and policies that addressed FGM/C-related prevention and management, several county-based participants noted that they were unfamiliar with the content of these laws and policies. Some of the county-based stakeholders explained that their limited knowledge stemmed from their non-involvement in formulation of the laws and policies. 
"2011 Prohibition of FGM Act yes, I don't know about the actual word perfectly, I cannot quote, but I know it is the one that prohibits and imposes a jail term, or a fine or both of them at the time, yeah."

Education sector officer, West Pokot County

"FGM is illegal in this country by law; as a health provider, we were not very much in the formulation of that law that disallowed FGM, but I know there is law and we use that law to dissuade because this is a community that circumcises the girls. That law has been used here to try and reduce that practise"

$$
\text { Health officer, West Pokot County }
$$

Medicalisation, though an emerging threat to FGM/C abandonment efforts, was reportedly not addressed in the policies. Additionally, a majority of participants felt that there was a lack of policies that addressed the management of FGM/C-related complications.

"The de-medicalisation policy is just a statement, it's not a detailed sort of document. Basically, it prohibits trained medical persons from carrying out FGM/C and particularly within institutions licensed to provide health care."

Representative of the Kenya Medical Practitioners and Dentists Council, Nairobi

"Most of the documents I've seen are fairly silent on management, because until recently it is when people started discussing about reconstructive surgeries, psychological and emotional management. So, most of the interventions previously have been targeted on either prohibiting or preventing."

Representative of the Kenya Medical Practitioners and Dentists Board, Nairobi

\section{Exclusion of health sector-relevant context in legal instruments}

Although the actors included those from health sector involved in policymaking, participants did not make any reference to legal instruments that were relevant and specific to health-sector responses to FGM/C-including medicalisation such as the Nurses Act and the Medical and Dentist Practitioner Act. Indeed, the practice of FGM/C per se is not explicitly addressed by these laws. The practice is not identified as an offence under the Medical Practitioners and Dentists Act (revised 2012) (Republic of Kenya 2012a), but the Act under Article 20(1) states that disciplinary proceedings may be instituted against a medical practitioner who commits an offence under the Penal Code or engages in "any infamous or disgraceful conduct in a professional respect." Similarly, the Nurses Act (revised 2012) (Republic of Kenya 2011) does not explicitly address $\mathrm{FGM} / \mathrm{C}$, but states that a nurse may be removed from the register if found guilty of misconduct by the Nursing Council of Kenya. Although these laws do not explicitly address FGM/C, they are applied, together with other national laws, while handling cases of omission and commission.

\section{Barriers to implementing FGM/C interventions at the county level}

Participants at the national and county levels highlighted several governance factors that limited implementation of FGM/C interventions at the county level. These included the lack of guidelines and strategies adapted for use at the county level; non-involvement of stakeholders from counties in the formulation of laws and policies, which was noted to lead to local resistance; lack of guidelines on the prevention and management of $\mathrm{FGM} / \mathrm{C}$; and the lack of supportive tools including information, education and communication (IEC) materials. These challenges are highlighted in the following quotes

"We are just using the national guidelines and strategies; there is none that has been domesticated specifically for West Pokot."

National Ministry of Health official, Nairobi

"Mostly you find they have formulated top to bottom where a team is picked from the national government. And then you get a few guys to come who may not necessarily be in 
touch in the ground they sit in a conference somewhere then now they make an attempt to disseminate. And by the time you come with a fully formed policy, people are resistant."

Representative of the Kenya Medical Practitioners and Dentists Council, Nairobi

"I don't think we have really specific guidelines; we need to come up with some. But in management of FGM it is just managed medically and symptomatically, the way we manage any other problem like bleeding."

Nurse tutor, West Pokot County

"At the community level, we don't have guidelines on prevention of FGM activities. But in terms of proper implementation of health talks in the community they can do it but they don't have even the IEC materials for prevention of FGM/C, and the key messages."

Public health officer, West Pokot County

In response to these challenges, some participants underscored the importance of involving grassroots stakeholders for successful implementation of anti-FGM policies in Kenya.

"I think the best model to adopt is to form caucuses at the grassroots with subsequent representation all the way to the national stage to articulate their issues. There are places which are hot spots for FGM, those few counties can be identified, and we start involving that. We do bottom up then we harmonise thoughts and come up with policies, which are actually acceptable to all the players."

Representative of the Kenya Medical Practitioners and Dentists Council, Nairobi

\section{Health information systems}

As noted by the WHO, "a well-functioning health information system ensures production, analysis, dissemination and use of reliable and timely information on health determinants, health system performance and health status" (WHO 2007). For example, maternal and child health departments keep data on the number of women and children who present for antenatal, postnatal, family planning, and immunisation services. These data can strengthen programming and policy, and inform the allocation of resources.

Service data abstraction results showed that while records on reproductive health services offered at health facilities in West Pokot were available, providers did not document the number of women with $\mathrm{FGM} / \mathrm{C}$ and/or complications stemming from the practice. Moreover, there were no specific data on women/girls who sought or received FGM/C-related interventions like counselling; deinfibulation; clitoral reconstruction; antibiotics for infection; painkillers; and surgical interventions for keloids, cysts, or scarring (Table 5).

Table 5. Number of clients who sought reproductive health services in service points that interfaced with girls/women with FGM/C in West Pokot County $(n=10)$

\begin{tabular}{|c|c|c|c|c|}
\hline & Last 12 months & $\begin{array}{l}\text { Last } 6 \\
\text { months }\end{array}$ & $\begin{array}{l}\text { Last } 1 \\
\text { month }\end{array}$ & $\begin{array}{l}\text { Facilities } \\
\text { with } \\
\text { missing } \\
\text { data }\end{array}$ \\
\hline Number of clients seen at service delivery points & 39548 & 31693 & 4555 & 5 \\
\hline \multicolumn{5}{|l|}{ Number of women/girls who attended antenatal care } \\
\hline $1^{\text {st }}$ trimester & 2663 & 1297 & 118 & 2 \\
\hline $2^{\text {nd }}$ trimester & 10981 & 5312 & 961 & 1 \\
\hline \multicolumn{5}{|c|}{ Number of women/girls with FGM/C who attended antenatal care } \\
\hline $1^{\text {st }}$ trimester & - & - & - & 10 \\
\hline $2^{\text {nd }}$ trimester & - & - & - & 10 \\
\hline $3^{\text {rd }}$ trimester & - & - & - & 10 \\
\hline \multicolumn{5}{|l|}{ Number of women/girls who attended post-natal care } \\
\hline after first week of delivery & 2334 & 1277 & 219 & 5 \\
\hline
\end{tabular}




\begin{tabular}{|c|c|c|c|c|}
\hline & Last 12 months & $\begin{array}{l}\text { Last } 6 \\
\text { months }\end{array}$ & $\begin{array}{l}\text { Last } 1 \\
\text { month }\end{array}$ & $\begin{array}{l}\text { Facilities } \\
\text { with } \\
\text { missing } \\
\text { data }\end{array}$ \\
\hline after six weeks of delivery & 26 & 11 & 2 & 6 \\
\hline \multicolumn{5}{|c|}{ Number of women/girls with FGM/C who attended post-natal care } \\
\hline after first week of delivery & - & - & - & 10 \\
\hline after six weeks of delivery & - & 3 & - & 9 \\
\hline $\begin{array}{l}\text { Number of women/girls who attended family } \\
\text { planning (FP) }\end{array}$ & 4406 & 2539 & 410 & 2 \\
\hline $\begin{array}{l}\text { Number of women/girls with FGM/C who attended } \\
\text { FP }\end{array}$ & - & - & - & 10 \\
\hline $\begin{array}{l}\text { Number of women/girls with FGM/C who attended } \\
\text { youth-friendly services }\end{array}$ & - & - & - & 10 \\
\hline $\begin{array}{l}\text { Number of women with type I FGM/C attending } \\
\text { service delivery points (SDPs) }\end{array}$ & - & - & - & 10 \\
\hline $\begin{array}{l}\text { Number of women with type II FGM/C attending } \\
\text { SDPs }\end{array}$ & - & - & - & 10 \\
\hline $\begin{array}{l}\text { Number of women with type III FGM/C attending } \\
\text { SDPs }\end{array}$ & - & - & - & 10 \\
\hline \multicolumn{5}{|l|}{ Number of women/girls with: } \\
\hline Immediate FGM/C complications & - & - & - & 10 \\
\hline Obstetric FGM/C complications & - & - & - & 10 \\
\hline Gynaecological FGM/C complications & - & - & - & 10 \\
\hline Sexual FGM/C complications & - & - & - & 10 \\
\hline Psychological FGM/C complications & - & - & - & 10 \\
\hline \multicolumn{5}{|l|}{ Number of women/girls who have undergone } \\
\hline FGM/C related counselling & - & - & - & 10 \\
\hline FGM/C related de-infibulation & - & - & - & 10 \\
\hline FGM/C-related clitoral reconstruction & - & - & - & 10 \\
\hline \multicolumn{5}{|l|}{ Number of women/girls with FGM/C who received } \\
\hline Antibiotics for infection & - & - & - & 10 \\
\hline Painkillers & - & - & - & 10 \\
\hline Surgical Interventions for (keloids, cyst, scarring) & - & - & - & 10 \\
\hline Referrals & - & - & - & 10 \\
\hline
\end{tabular}

A common theme in the interviews/discussions was that the health system rarely collected data on FGM/C cases including the complications. Reasons for the limited collection of FGM/C-related data included the low priority placed on the practise relative to other health issues such as HIV and malaria. The lack of data was viewed as a barrier to planning, programming, and resource allocation.

"We don't capture the data on how many girls or women came into the health facility because of FGM or related deaths, what caused the death? I don't know whether if you go to those facilities to look for such kind of data you will get it ... So that brings in the medical board to come up with a way where they can capture all the data..."

representative from an NGO dealing with legal issues for women

"The issue of medical coding relevant to FGM/C is neglected. It will be very important for the Health Information Management System to capture complications related to FGM since currently they are not recorded. For example, it's through FGM that there will be prolonged labour. But this something is not captured within the health system or recorded in the health 
system. The health system focus is more on those indicators such as how many people have malaria, how many have HIV and those other pressing issues, thus FGM issues are neglected. The health practitioners coming from communities who perceive FGM as a normal rite of passage for girls they don't see it as a form of violation".

UN organisation representative, Nairobi

"All along we keep referring to the KDHS, and we all know it's like done every five years and not very specific to the needs of the health sector. They basically have data on prevalence, which is important. But in terms of the health sector, we don't know how many women are presenting with those complications. How many health workers have been trained on managing this specifically, trained for managing FGM and providing care, we do not have data on who is actually carrying out FGM. So, it's really difficult to justify policy change without evidence, that is why we have seen the need to collect that data, to advise policy change, and to advise on allocation of resources."

Ministry of Health Representative, Nairobi

In efforts to address the gap in data on FGM/C, a Ministry of Health representative noted that the Ministry was working to include FGM/C indicators in the Health Management Information System (HMIS) to facilitate the collection of FGM/C-related data at service delivery points interfacing with women/girls with $\mathrm{FGM} / \mathrm{C}$.

"And of late for FGM, specifically FGM, we are in the process of ensuring that we have indicators in the Kenya indicator manual, the Ministry of Health indicator manual, which spells out and describes all the indicators that are used to collect data within the health sector. So, we're in the process of getting FGM indicators into that manual. So that now we can begin to collect health sector-specific data, which we haven't had all through."

Ministry of Health Representative, Nairobi

\section{Financing}

A good health financing system ensures that there are adequate financial resources to cater for health services and to ensure that people are protected against costly services (WHO 2007). Although the health system in West Pokot provided essential services, FGM/C-related management and prevention interventions faced some financial challenges. Most participants cited the lack of budget or resource allocation by the county government as a barrier to the implementation of FGM/C-related prevention in health facilities. Participants noted that a majority of the funding was provided by NGOs, but that this funding was inadequate, thus limiting the reach of interventions.

"So how do we make sure that we also have a certain percentage, typically going to issues of policy implementation in FGM. The African Union, member states are required to budget for resources for ending FGM by 2030. And for me I think there should just be a budget specifically for FGM policy implementation before 2030."

National government officer, Nairobi

"I think $100 \%$ of the resource usually come from the NGOs that were fighting against FGM and not the government."

Chairlady, women's CBO, West Pokot

"The NGOs are only reaching a small percentage in the community, like here in West Pokot we have only three NGOs that are working to fight against FGM, but are not covering the whole county. The other parts are not accessible, but it would now be part of the county 
government, so in that case I could say that the resources are not sufficient to reach the whole county."

County government development officer, West Pokot

\section{Health workforce}

A well-performing health workforce is responsive, productive, competent, and efficient (WHO 2007). Participants noted that providers' inadequate training on FGM/C was a hindrance to provision of quality services. They explained, for example, that few providers were trained on techniques such as de-infibulation.

"There are these issues of like de-infibulation, though many staff have not been trained. We lack support for the training of staff who are actually working in the maternity but for the few that have been trained, when there is a serious case of FGM they can be able to perform that procedure and help the survivor."

\section{Public health nurse, West Pokot}

A representative from the national Ministry of Health in Nairobi, noted that a training manual was under development to build healthcare providers' capacity to provide specific FGM/C-related interventions.

"Previously, health workers will manage FGM cases, victims, like any other patient. That is really not something that we routinely follow up, but we are hoping with the training manual, they are able to identify and even document."

Results from the client-provider interactions showed that while a majority of primary $(88 \%)$, secondary (82\%), and all tertiary health facilities had the requisite equipment to address common ailments, most service providers had inadequate knowledge of FGM/C (Table 6). Capacity-building of healthcare providers was therefore noted to be an important strategy to implement $\mathrm{FGM} / \mathrm{C}$ prevention interventions.

"What is very important when it comes to the health workers is creating capacity for them to share messages on FGM/C-related complications with the community."

Ministry of Health Representative, Nairobi

Table 6. Availability of health facility infrastructural and human capacity to respond to FGM/C $(n=61)$

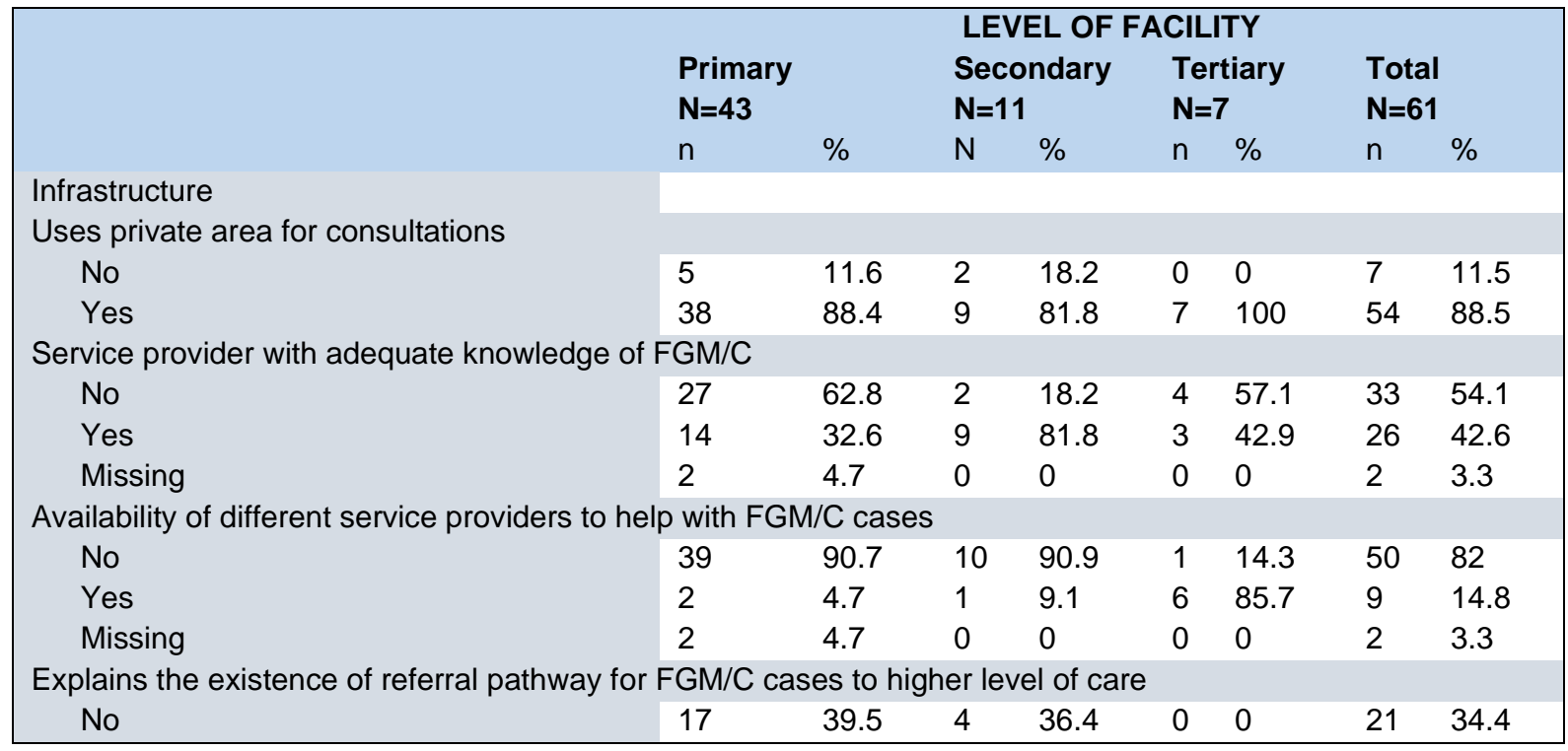




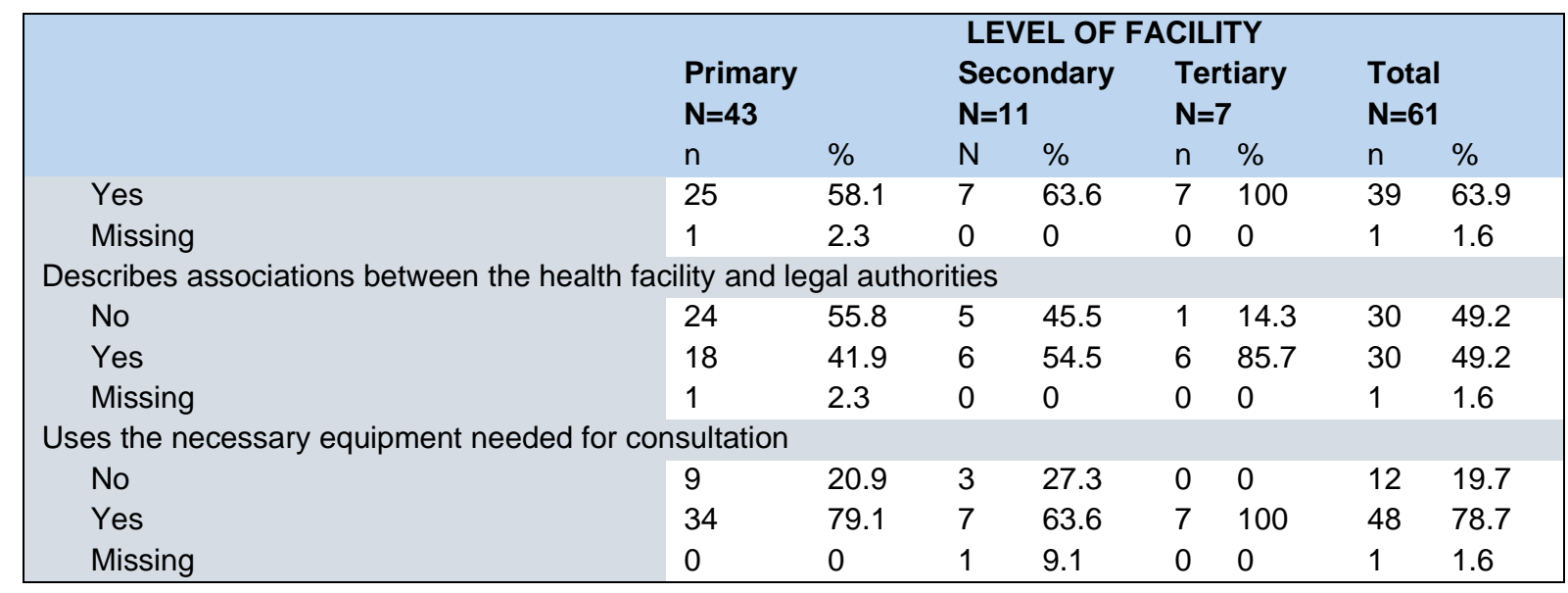

\section{Service delivery}

The WHO framework defines good service as effective, safe, and quality health interventions that are delivered to those who need them with prudent use of resources (WHO 2007). There were two categories of services that were provided by the health system and FGM/C programme implementers-health facility-based services and community-based interventions.

The health facilities offered HIV screening and testing (100\%); antenatal care (100\%); child growth monitoring and immunisation (100\%); family planning (97\%); gynaecological (97\%); delivery $(97 \%)$, and postpartum care $(97 \%)$, essential newborn care $(87 \%)$, screening for sexually transmitted infections (STIs) and treatment (80\%), infertility consultation (43\%), and (37\%) HIV/AIDS treatment and care (37\%). However, specific FGM/C-related interventions were only offered in $23 \%$ of all facilities (Table 7 ).

Table 7. Reproductive health and FGM/C-related services sought by women across facilities in West Pokot County $(n=30)$

\begin{tabular}{|c|c|c|c|c|c|c|c|c|}
\hline & \multirow{2}{*}{$\begin{array}{l}\text { Primary } \\
\mathrm{N}=25 \\
\mathrm{n}\end{array}$} & \multirow[b]{2}{*}{$\%$} & \multicolumn{2}{|c|}{$\begin{array}{l}\text { Secondary } \\
\mathrm{N}=4\end{array}$} & \multicolumn{2}{|c|}{$\begin{array}{l}\text { Tertiary } \\
\mathrm{N}=1\end{array}$} & \multicolumn{2}{|c|}{$\begin{array}{l}\text { Total } \\
\mathrm{N}=30\end{array}$} \\
\hline & & & $\mathrm{n}$ & $\%$ & $\mathrm{n}$ & $\%$ & $\mathrm{n}$ & $\%$ \\
\hline Reproductive health services & & & & & & & & \\
\hline STI screening and treatment & 19 & 76.0 & 4 & 100.0 & 1 & 100.0 & 24 & 80.0 \\
\hline HIV screening, testing, and counselling & 25 & 100.0 & 4 & 100.0 & 1 & 100.0 & 30 & 100.0 \\
\hline HIV/AIDS treatment and care & 6 & 24.0 & 4 & 100.0 & 1 & 100.0 & 11 & 36.7 \\
\hline Family planning counselling & 25 & 100.0 & 3 & 75.0 & 1 & 100.0 & 29 & 96.7 \\
\hline Infertility consultation & 10 & 40.0 & 2 & 50.0 & 1 & 100.0 & 13 & 43.3 \\
\hline Gynaecological services & 24 & 96.0 & 4 & 100.0 & 1 & 100.0 & 29 & 96.7 \\
\hline Specific FGM/C management & 4 & 16.0 & 3 & 75.0 & 0 & 0.0 & 7 & 23.3 \\
\hline Antenatal care & 25 & 100.0 & 4 & 100.0 & 1 & 100.0 & 30 & 100.0 \\
\hline Delivery & 24 & 96.0 & 4 & 100.0 & 1 & 100.0 & 29 & 96.7 \\
\hline Postpartum care & 24 & 96.0 & 4 & 100.0 & 1 & 100.0 & 29 & 96.7 \\
\hline Essential newborn care & 22 & 88.0 & 3 & 75.0 & 1 & 100.0 & 26 & 86.7 \\
\hline Child growth monitoring and immunisation & 25 & 100.0 & 4 & 100.0 & 1 & 100.0 & 30 & 100.0 \\
\hline
\end{tabular}

\section{FGM/C-related complications}

Participants noted that patients with FGM/C presented with a wide range of complications. These complications included bleeding; birth complications such as obstructed labour and postpartum haemorrhage; infections; and long-term complications such as fistulas, scars, and keloids. 
Participants noted that fistulas were associated with prolonged and/or obstructed labour as a result of the inelastic scar resulting from FGM/C as well as the pinhole passage for those who were infibulated. Women were also reported to develop scars on their external genitalia that were generally left untreated unless they were severe.

Participants also noted that women living with FGM/C experienced sexual and psychological complications. As illustrated in the following quotes, the sexual complications included difficulty in penetration due to infibulation, painful intercourse, and the lack of sexual enjoyment. Psychological complications, on the other hand, included psychological trauma and stigma.

"The one that underwent circumcision, because of narrowed vaginal canal, when she meets a man (sexual intercourse), there is a struggle until she developed tears."

Nurse/midwife, FGD

"I have seen a lady with FGM/C who was divorced because of keloids because the husband could not enter, they could not make love, it was difficult because they were all over and they divorced."

Midwife, Sub-county Hospital

"When you have sexual intercourse with a man, there must be pain. These young girls cannot come in contact with a man for the first three days; they just try around the outside part (genitalia) until when it slides in. But then there is so much pain. After three days they meet once again. The pain is unbearable."

Woman with FGM/C, FGD

"I want to imagine the ladies are left with so much pain especially when the skin around the vagina [is] brought together haphazardly during the procedure thereafter the woman suffers a lot of painful sex and no enjoyment."

Medical doctor, County referral hospital

"Girls are at times forced to undergo that FGM, others are being taken away from school. The psychological trauma that these people undergo is because others are forced to against their will."

Healthcare provider, West Pokot County

"Also ... stigmatisation, you know currently people don't want FGM and if you find someone who has done FGM and people [are] talking about the bad effects, you will find that deep inside her, she will be feeling some form of stigmatisation."

Nurse/midwife, Dispensary

\section{Management of FGM-related complications}

A summary of illustrative quotes describing how FGM/C-related complications were managed is provided in Table 8. As women in West Pokot traditionally undergo type III (infibulation) FGM/C, the management interventions for birth complications associated with FGM/C presenting with obstructed labour included episiotomies, de-infibulation, and caesarean sections. Although some participants noted that healthcare providers in West Pokot offered counselling to clients with FGM/C-related complications, the client-provider interaction results showed that healthcare providers failed to identify FGM/C during interactions with the clients. 
Table 8. Illustrative quotes on the management of FGM/C-related complications

\begin{tabular}{|c|c|}
\hline Complication & Management \\
\hline Birth complications & $\begin{array}{l}\text { "The possible complications are difficulties in giving birth and delivering the } \\
\text { baby because of the FGM scar. This requires having to do episiotomies which } \\
\text { would otherwise be unwarranted to allow for passage of the baby." Medical } \\
\text { doctor, West Pokot County } \\
\text { "During delivery this mother with FGM/C who has difficulty in delivery, we } \\
\text { usually assist [her] by performing some surgical intervention called episiotomy } \\
\text { so that the birth canal can be roomy enough for the mother to deliver and that } \\
\text { is repaired of course after the delivery of the baby." Midwife, County referral } \\
\text { hospital } \\
\text { "Most ladies when they come during labour, they have obstructed labour and } \\
\text { difficulty in delivery and that means delivery is a problem; most [of] them end } \\
\text { up in a theatre for caesarean section." Nurse/midwife County referral hospital }\end{array}$ \\
\hline Bleeding & $\begin{array}{l}\text { "Complication of FGM... includes bleeding which can even lead to death. The } \\
\text { first thing we do is to arrest the bleeding through suturing, because with FGM } \\
\text { they cut too deep or cut a vein or artery. Therefore, one has to manage the } \\
\text { bleeding before you do anything else." Nurse/midwife, Dispensary, West Pokot } \\
\text { County } \\
\text { "We assess the extent of blood loss, grouping and cross-matching before } \\
\text { initiating the blood transfusion. Once the transfusion is done, we can recheck } \\
\text { the haemoglobin level and keep monitoring the patient." Clinical officer, County } \\
\text { referral hospital, West Pokot }\end{array}$ \\
\hline Infections & $\begin{array}{l}\text { "It depends with the severity; if the patient has come who is so severe we } \\
\text { normally admit, we give fluids, give IV antibiotics, and we clean if there is a } \\
\text { wound. For the minor, the minor case, we clean and we give oral antibiotics } \\
\text { and we make follow-ups at times; we tell them to report if there are any } \\
\text { complications that arise...." Healthcare provider, West Pokot County }\end{array}$ \\
\hline Scarring & $\begin{array}{l}\text { "Severe scar may require reconstructive surgery and that sometimes is not } \\
\text { done since the level of expertise down in this marginalised county is actually } \\
\text { really poor, and I want to imagine these ladies are left with so much pain." } \\
\text { Clinical officer, Sub-county referral hospital }\end{array}$ \\
\hline
\end{tabular}

In most primary (88\%) and secondary (55\%) facilities providers did not ask their clients about FGM/C. Only healthcare providers in three primary- and two secondary-level facilities asked their patients about the severity of $\mathrm{FGM} / \mathrm{C}$, while healthcare providers in four primary- and three secondary-level facilities asked their clients about possible effects of FGM/C (Table 9). None of the providers at the tertiary level enquired about patients' FGM/C status nor the possible effects of having undergone $\mathrm{FGM} / \mathrm{C}$. Some of the qualitative interview results suggest that the lack of attention to FGM/C may have stemmed from the lack of guidelines around the management of $\mathrm{FGM} / \mathrm{C}$ complications resulting in these complications being treated symptomatically.

"Health workers will manage FGM cases, like any other patient, so that if they present with acute bleeding, then you manage the presenting symptoms. If they present with obstructed labour, then you manage the obstruction, but you're not very keen on what caused the obstruction."

\section{National government officer of health, Nairobi}

"Even if it's something (FGM/C) which was done illegally, when it has reached our hands, we need to treat as a patient, as somebody vulnerable. Not to start to ask who told you to do that without discrimination. So, you treat/manage accordingly; for example, if its bleeding, infection you manage accordingly as signs and symptoms present to you."

Reproductive health coordinator, West Pokot County 
Table 9. Healthcare providers' identification of FGM/C while interacting with clients ( $n=61$ )

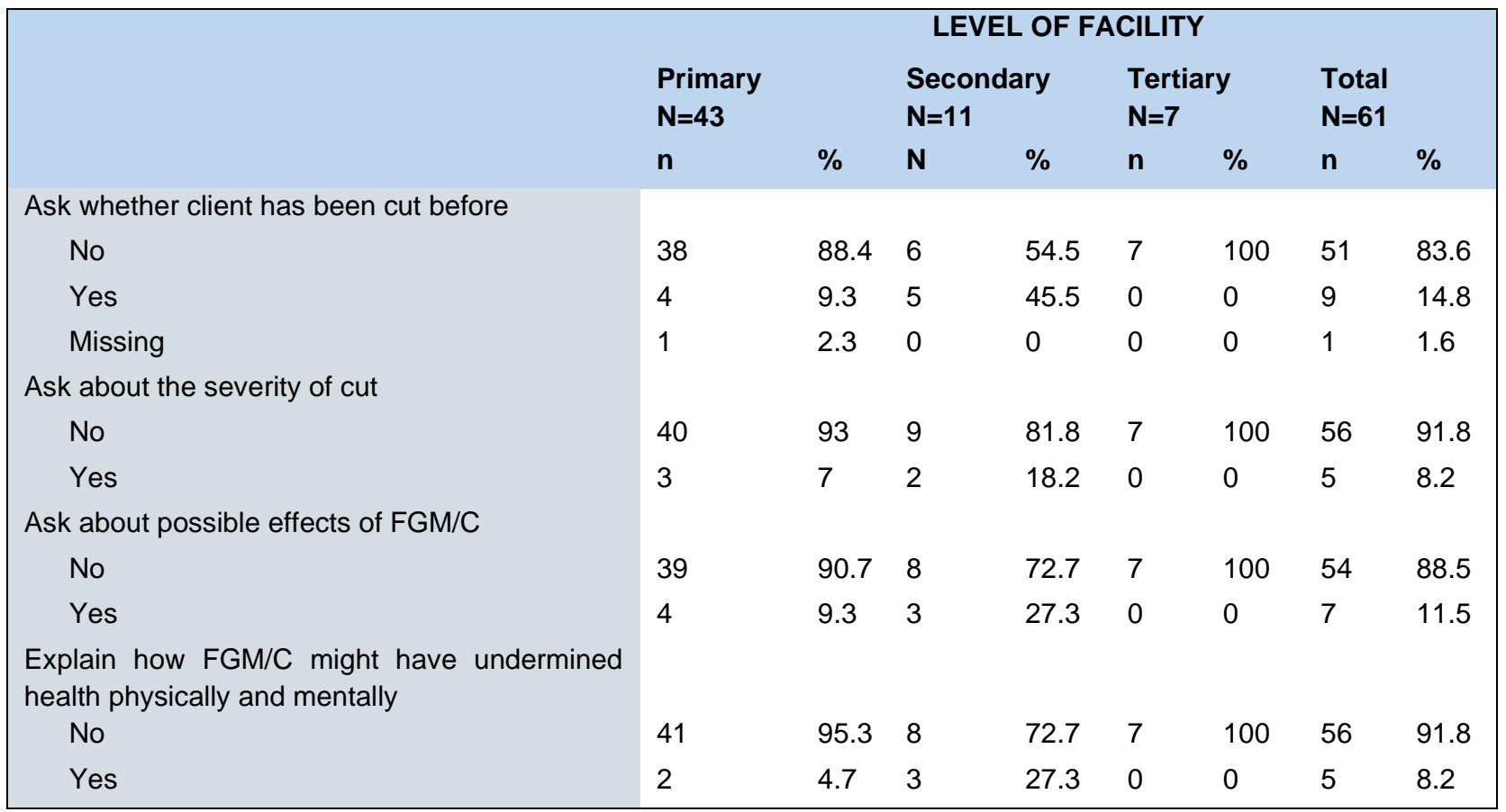

Further, client exit interview data suggested that while most (99\%) service providers explained about care interventions or provided treatment instructions to the clients with reproductive health problems other than FGM/C (89\%), very few providers explained the negative consequences of FGM/C (16\%) or discussed the need for clients to stop practising FGM/C (15\%) (Table 10).

Table 10. Client-reported counselling practises among clients who sought reproductive services across health facilities $(n=360)$.

\begin{tabular}{|c|c|c|c|c|c|c|c|c|}
\hline \multirow[t]{3}{*}{ Communication } & \multicolumn{8}{|c|}{ FACILITY LEVEL } \\
\hline & \multicolumn{2}{|c|}{$\begin{array}{l}\text { Primary } \\
\mathrm{N}=220\end{array}$} & \multicolumn{2}{|c|}{$\begin{array}{l}\text { Secondary } \\
N=98\end{array}$} & \multicolumn{2}{|c|}{$\begin{array}{l}\text { Tertiary } \\
\mathrm{N}=42\end{array}$} & \multicolumn{2}{|c|}{$\begin{array}{l}\text { Total } \\
\mathrm{N}=360\end{array}$} \\
\hline & (n) & $\%$ & (n) & $\%$ & (n) & $\%$ & (n) & $\%$ \\
\hline \multicolumn{9}{|c|}{ Did the provider explain to you what he/she is managing and why? } \\
\hline No & (16) & 7.3 & (11) & 11.2 & (5) & 11.9 & 32 & 8.9 \\
\hline Yes & (204) & 92.7 & (86) & 87.8 & (37) & 88.1 & 327 & 90.8 \\
\hline Missing & (0) & 0 & (1) & 1 & (0) & 0 & 1 & 0.3 \\
\hline \multicolumn{9}{|c|}{ Did the provider explain the treatment instructions? } \\
\hline No & 23 & 10.5 & 10 & 10.2 & 5 & 11.9 & 38 & 10.6 \\
\hline Yes & 196 & 89.1 & 88 & 89.8 & 37 & 88.1 & 321 & 89.2 \\
\hline Missing & 1 & 0.5 & 0 & 0 & 0 & 0 & 1 & 0.3 \\
\hline \multicolumn{9}{|c|}{ Did the provider explain to you the negative consequences of $\mathrm{FGM} / \mathrm{C}$ ? } \\
\hline No & 180 & 81.8 & 83 & 85 & 39 & 93 & 302 & 84 \\
\hline Yes & 40 & 18.2 & 15 & 15 & 3 & 7.1 & 58 & 16 \\
\hline \multicolumn{9}{|c|}{ Did the provider discuss with you the need to stop practicing FGM/C? } \\
\hline No & 181 & 82.3 & 84 & 85.7 & 39 & 92.9 & 304 & 84.4 \\
\hline Yes & 38 & 17.3 & 14 & 14.3 & 3 & 7.1 & 55 & 15.3 \\
\hline Missing & 1 & 0.5 & 0 & 0 & 0 & 0 & 1 & 0.3 \\
\hline \multicolumn{9}{|c|}{ During your visit today, were you given any information on follow-up care? } \\
\hline No & 62 & 28 & 14 & 14.3 & 8 & 19 & 84 & 23.3 \\
\hline Yes & 158 & 72 & 84 & 85.7 & 34 & 81 & 276 & 76.7 \\
\hline \multicolumn{9}{|c|}{ During your visit today, were you given an appointment for a follow-up visit? } \\
\hline No & 2 & 1.3 & 1 & 1.2 & 2 & 5.7 & 5 & 1.8 \\
\hline Yes & 157 & 99 & 84 & 98.8 & 33 & 94.3 & 274 & 98.2 \\
\hline
\end{tabular}




\begin{tabular}{|c|c|c|c|c|c|c|c|c|}
\hline \multirow[t]{3}{*}{ Communication } & \multicolumn{8}{|c|}{ FACILITY LEVEL } \\
\hline & \multicolumn{2}{|c|}{$\begin{array}{l}\text { Primary } \\
\mathrm{N}=220\end{array}$} & \multicolumn{2}{|c|}{$\begin{array}{l}\text { Secondary } \\
N=98\end{array}$} & \multicolumn{2}{|c|}{$\begin{array}{l}\text { Tertiary } \\
\mathrm{N}=42\end{array}$} & \multicolumn{2}{|c|}{$\begin{array}{l}\text { Total } \\
\mathrm{N}=360\end{array}$} \\
\hline & (n) & $\%$ & (n) & $\%$ & (n) & $\%$ & (n) & $\%$ \\
\hline No & 205 & 93.2 & 96 & 98 & 37 & 88.1 & 338 & 93.9 \\
\hline Yes & 8 & 3.6 & 1 & 1 & 3 & 7.1 & 12 & 3.3 \\
\hline Missing & 7 & 3.2 & 1 & 1 & 2 & 4.8 & 10 & 2.8 \\
\hline
\end{tabular}

As shown in Table 11, most providers in primary (86\%), secondary $(55 \%)$, and tertiary $(71 \%)$ facilities failed to educate or advise clients on approaches for prevention of $F G M / C$ for their daughters.

Table 11. Interventions related to FGM/C prevention across health facilities in West Pokot $(n=61)$

\begin{tabular}{|c|c|c|c|c|c|c|c|c|}
\hline \multirow[b]{3}{*}{ Interventions for FGM/C prevention } & \multicolumn{8}{|c|}{ LEVEL OF FACILITY } \\
\hline & \multicolumn{2}{|c|}{$\begin{array}{l}\text { Primary } \\
(\mathrm{N}=43)\end{array}$} & \multicolumn{2}{|c|}{$\begin{array}{l}\text { Secondary } \\
(\mathrm{N}=11)\end{array}$} & \multicolumn{2}{|c|}{$\begin{array}{l}\text { Tertiary } \\
(\mathrm{N}=7)\end{array}$} & \multicolumn{2}{|c|}{ Total $(\mathrm{N}=61)$} \\
\hline & n & $\%$ & n & $\%$ & n & $\%$ & $\mathbf{n}$ & $\%$ \\
\hline \multicolumn{9}{|c|}{ Education and advice relating to the prevention of FGM/C } \\
\hline No & 37 & 86 & 6 & 54.5 & 5 & 71.4 & 48 & 78.7 \\
\hline Yes & 6 & 14 & 5 & 45.5 & 1 & 14.3 & 12 & 19.7 \\
\hline Missing & 0 & 0 & 0 & 0 & 1 & 14.3 & 1 & 1.6 \\
\hline \multicolumn{9}{|c|}{ Availability of link to the authorities to report potential risk due to FGM/C } \\
\hline No & 30 & 69.8 & 7 & 63.6 & 3 & 42.9 & 40 & 65.6 \\
\hline Yes & 13 & 30.2 & 4 & 36.4 & 3 & 42.9 & 20 & 32.8 \\
\hline Missing & 0 & 0 & 0 & 0 & 1 & 14.3 & 1 & 1.6 \\
\hline \multicolumn{9}{|l|}{ Existence of mechanism for follow-up } \\
\hline No & 31 & 72.1 & 10 & 90.9 & 2 & 28.6 & 43 & 70.5 \\
\hline Yes & 11 & 25.6 & 1 & 9.1 & 4 & 57.1 & 16 & 26.2 \\
\hline Missing & 1 & 2.3 & 0 & 0 & 1 & 14.3 & 2 & 3.3 \\
\hline \multicolumn{9}{|c|}{ Provision of IEC-related materials to help with reinforcement of prevention } \\
\hline No & 43 & 100 & 8 & 72.7 & 6 & 85.7 & 57 & 93.4 \\
\hline Yes & 0 & 0 & 3 & 27.3 & 0 & 0 & 3 & 4.9 \\
\hline Missing & 0 & 0 & 0 & 0 & 1 & 14.3 & 1 & 1.6 \\
\hline \multicolumn{9}{|c|}{ Existence of link with local community civil groups and gatekeepers to help } \\
\hline No & 26 & 60.5 & 4 & 36.4 & 3 & 42.9 & 33 & 54.1 \\
\hline Yes & 16 & 37.2 & 7 & 63.6 & 3 & 42.9 & 26 & 42.6 \\
\hline Missing & 1 & 2.3 & 0 & 0 & 1 & 14.3 & 2 & 3.3 \\
\hline \multicolumn{9}{|c|}{ Possible outreaches to the community to help with prevention of FGM/C } \\
\hline No & 31 & 72.1 & 6 & 54.5 & 3 & 42.9 & 40 & 65.6 \\
\hline Yes & 11 & 25.6 & 5 & 45.5 & 3 & 42.9 & 19 & 31.1 \\
\hline Missing & 1 & 2.3 & 0 & 0 & 1 & 14.3 & 2 & 3.3 \\
\hline
\end{tabular}

\section{Challenges faced by healthcare providers in the clinical management of FGM/C}

Participants noted that they faced several challenges when managing patients with FGM/C-related complications. These included a lack of essential lifesaving resources like blood banks that were critical for managing heavy bleeding, and the lack of guidelines on the management of $\mathrm{FGM} / \mathrm{C}$ complications. Further, participants noted that many facilities lacked skilled providers, which resulted in patients being referred to higher-level facilities for treatment. These challenges are illustrated in the following quotes:

"Mostly like here we don't have a blood bank. So, if patients come with a lot of bleeding, we just refer them. We don't have a blood bank so that that blood transfusion cannot be conducted." 
"According to our facility we are still below average in terms of quality because currently we don't have a gynaecologist and we have a deficit of doctors also so in terms of management of complications we are still below average. The shortage has affected such that we cannot handle conditions like fistulas"

Nurse/midwife, FGD, Faith-based hospital

"Most of the documents I've seen are fairly silent on management of FGM/C. It is until recently when people started discussing about reconstructive surgeries, psychological and emotional management. So, most of the interventions previously have been targeted on either prohibiting or preventing the practice."

Representative of the Kenya Medical Practitioners and Dentists Board, Nairobi

"In the previous documents there is nothing that was talking about specifically FGM/C management, breaking it down for the health worker on how they're supposed to manage the specific complications."

National Ministry of Health officer, Nairobi

Some healthcare providers expressed challenges in conducting de-infibulation as a result of inadequate knowledge and skills or resistance from the clients. Furthermore, some clients were reported to request re-infibulation after de-infibulation during the birthing process.

“We just try though we don't have enough knowledge on how to manage the complications, but one tries whatever [one] can. But I feel we need to have some, or more knowledge on how to perform de-infibulation because it is not easy to assist the woman whose episiotomy is already done at home."

Nurse/midwife, Sub-county hospital

"There are some women we encounter, and we want to de-infibulate and they say no, don't do it blah blah. So, you know it's hard for one to deliver so we told them it's hard for you to deliver if you can't de-infibulate, so we have to do it."

Medical Doctor, County referral hospital

"So, the women request please after delivery, you can close it, so sometimes it's as per the women's request. If they insist, they want it closed, we just close. Yes, most of the time it is as for their request, there is nothing much I can do if she says so. Because even if you say you will leave it open and the woman decides to close. They will always look for somewhere to close it \{laughter\}. Yeah, they will always get out of the ward."

Clinical officer, County referral hospital

"Then you know it's traditional, because in this marriage, may be the husband may not be okay with the genitalia being open. The woman could be left (divorced) or the husband remarries another woman."

Nurse/midwife, Sub-county hospital

\section{Referrals}

In instances where providers were unable to provide care for FGM/C-related complications, patients were referred to higher-level facilities for management.

"We do refer and link with [the] county referral hospital ... if we can't manage it, we refer to them. Most of the time we handle the normal delivery procedures, the abnormal we don't."

Nurse/midwife, health centre

"The woman has prolonged labour ... because there is no way this baby can come out. FGM/C obstructs the baby from coming out and the woman labours for [a] long time. Most of the women coming from our peripheries, health facilities or communities come with prolonged and obstructed labour. So, by time they reach the county hospital, they are helped to deliver through caesarean section."

Midwife, West Pokot county hospital 
As shown in shown Table 12, referral systems to higher-level facilities existed in all primary, tertiary, and in some (25\%) secondary facilities. FGM/C-related referrals were found in $63 \%$ of all facilities. The nature of the referrals for FGM/C cases was for birth (48\%), gynaecological issues $(32 \%)$, and immediate (11\%) complications. Additionally, the client-provider interactions data showed that there were referral pathways for $F G M / C$ cases.

Table 12. Referrals for clients with various reproductive health problems $(n=30)$

\begin{tabular}{|c|c|c|c|c|c|c|c|c|}
\hline & \multicolumn{2}{|c|}{ Primary } & \multicolumn{2}{|c|}{ Secondary } & \multicolumn{2}{|c|}{ Tertiary } & \multicolumn{2}{|c|}{ Total } \\
\hline & $\mathbf{n}$ & $\%$ & $\mathbf{N}$ & $\%$ & $\mathbf{N}$ & $\%$ & $\mathbf{n}$ & $\%$ \\
\hline Existence of referral system to higher-level facilities & 25 & 100.0 & 4 & 100.0 & 1 & 100.0 & 30 & 100.0 \\
\hline \multicolumn{9}{|l|}{ Average number of referrals done per week } \\
\hline Rare & 1 & 4.0 & 0 & 0.0 & 0 & 0.0 & 1 & 3.3 \\
\hline 1 & 14 & 56.0 & 0 & 0.0 & 0 & 0.0 & 14 & 46.7 \\
\hline 2 & 5 & 20.0 & 0 & 0.0 & 0 & 0.0 & 5 & 16.7 \\
\hline 3 to 7 & 2 & 8.0 & 4 & 100.0 & 0 & 0.0 & 6 & 20.0 \\
\hline Missing & 3 & 12.0 & 0 & 0.0 & 1 & 100.0 & 4 & 13.3 \\
\hline \multicolumn{9}{|l|}{ Availability of tools/documents used for referral } \\
\hline No & 1 & 4.0 & 0 & 0.0 & 0 & 0.0 & 1 & 3.3 \\
\hline Yes & 23 & 92.0 & 4 & 100.0 & 1 & 100.0 & 28 & 93.3 \\
\hline Missing & 1 & 4.0 & 0 & 0.0 & 0 & 0.0 & 1 & 3.3 \\
\hline \multicolumn{9}{|l|}{ Services clients referred for $(Y e s=n)$ : } \\
\hline $\mathrm{FGM} / \mathrm{C}$ & 15 & 60.0 & 3 & 75.0 & 1 & 100.0 & 19 & 63.3 \\
\hline STI & 8 & 32.0 & 1 & 25.0 & 0 & 0.0 & 9 & 30.0 \\
\hline HIV/AIDS & 19 & 76.0 & 2 & 50.0 & 0 & 0.0 & 21 & 70.0 \\
\hline Family planning & 8 & 32.0 & 3 & 75.0 & 0 & 0.0 & 11 & 36.7 \\
\hline Antenatal care & 12 & 48.0 & 3 & 75.0 & 1 & 100.0 & 16 & 53.3 \\
\hline Postpartum care & 10 & 40.0 & 2 & 50.0 & 0 & 0.0 & 12 & 40.0 \\
\hline Essential newborn care & 10 & 40.0 & 2 & 50.0 & 0 & 0.0 & 12 & 40.0 \\
\hline Child immunisation & 1 & 4.0 & 0 & 0.0 & 0 & 0.0 & 1 & 3.3 \\
\hline Others & 5 & 20.0 & 1 & 25.0 & 0 & 0.0 & 6 & 20.0 \\
\hline \multicolumn{9}{|l|}{ Nature of referred FGM/C cases } \\
\hline Birth complications & 8 & 53.3 & 1 & 33.3 & 0 & 0.0 & 9 & 47.4 \\
\hline Gynaecological complications & 4 & 26.7 & 1 & 33.3 & 1 & 100.0 & 6 & 31.6 \\
\hline Immediate complications & 2 & 13.3 & 0 & 0.0 & 0 & 0.0 & 2 & 10.5 \\
\hline Missing & 1 & 6.7 & 1 & 33.3 & 0 & 0.0 & 2 & 10.5 \\
\hline \multicolumn{9}{|l|}{ Feedback after referral } \\
\hline No & 18 & 72.0 & 2 & 50.0 & 1 & 100.0 & 21 & 70.0 \\
\hline Yes & 7 & 28.0 & 2 & 50.0 & 0 & 0.0 & 9 & 30.0 \\
\hline
\end{tabular}

\section{Community-based services}

The health facility assessment showed that health talks were offered in some facilities, and the platforms for these talks were antenatal (57\%) and postnatal (37\%) assemblies for clients. The topics covered during the talks included HIV/AIDS, family planning, nutrition, pregnancy/labour and delivery, newborn care, and immunisation. Only $23 \%$ of the health facilities discussed $\mathrm{FGM} / \mathrm{C}$ during the health talks (Table 13). 
Table 13. FGM-related health talks conducted at service points within the health facilities

\begin{tabular}{|c|c|c|c|c|c|c|c|c|}
\hline & \multicolumn{2}{|c|}{ Primary } & \multicolumn{2}{|c|}{ Secondary } & \multicolumn{2}{|c|}{ Tertiary } & \multicolumn{2}{|c|}{ Total } \\
\hline & $\mathbf{n}$ & $\%$ & $\mathbf{n}$ & $\%$ & $\mathbf{n}$ & $\%$ & $\mathbf{n}$ & $\%$ \\
\hline \multicolumn{9}{|l|}{ Frequency of health talk per week } \\
\hline None & 1 & 4.0 & 0 & 0.0 & 0 & 0.0 & 1 & 3.3 \\
\hline Once & 9 & 36.0 & 1 & 25.0 & 0 & 0.0 & 10 & 33.3 \\
\hline Twice & 4 & 16.0 & 1 & 25.0 & 0 & 0.0 & 5 & 16.7 \\
\hline 3-4 times & 0 & 0.0 & 0 & 0.0 & 0 & 0.0 & 0 & 0.0 \\
\hline 5 times & 8 & 32.0 & 0 & 0.0 & 0 & 0.0 & 8 & 26.7 \\
\hline Daily & 2 & 8.0 & 1 & 25.0 & 0 & 0.0 & 3 & 10.0 \\
\hline Missing & 1 & 4.0 & 1 & 25.0 & 1 & 100.0 & 3 & 10.0 \\
\hline \multicolumn{9}{|l|}{ Platform of health talk } \\
\hline Antenatal gathering & 14 & 56.0 & 2 & 50.0 & 1 & 100.0 & 17 & 56.7 \\
\hline Postnatal gathering & 9 & 36.0 & 2 & 50.0 & 0 & 0.0 & 11 & 36.7 \\
\hline Part of youth-friendly services & 1 & 4.0 & 0 & 0.0 & 0 & 0.0 & 1 & 3.3 \\
\hline Others & 17 & 68.0 & 3 & 75.0 & 0 & 0.0 & 20 & 66.7 \\
\hline \multicolumn{9}{|l|}{ Topics covered } \\
\hline FGM/C & 6 & 24.0 & 1 & 25.0 & 0 & 0.0 & 7 & 23.3 \\
\hline STI & 16 & 64.0 & 4 & 100.0 & 1 & 100.0 & 21 & 70.0 \\
\hline HIV/AIDS & 22 & 88.0 & 4 & 100.0 & 1 & 100.0 & 27 & 90.0 \\
\hline Family planning & 22 & 88.0 & 4 & 100.0 & 1 & 100.0 & 27 & 90.0 \\
\hline Nutrition & 21 & 84.0 & 4 & 100.0 & 1 & 100.0 & 26 & 86.7 \\
\hline Pregnancy/labour and delivery & 21 & 84.0 & 4 & 100.0 & 1 & 100.0 & 26 & 86.7 \\
\hline Newborn care & 19 & 76.0 & 4 & 100.0 & 1 & 100.0 & 24 & 80.0 \\
\hline Immunisation & 21 & 84.0 & 4 & 100.0 & 1 & 100.0 & 26 & 86.7 \\
\hline Others & 3 & 12.0 & 1 & 25.0 & 0 & 0.0 & 4 & 13.3 \\
\hline
\end{tabular}

A children's officer in West Pokot noted that there were no FGM/C-specific outreach programmes saying:

"You know for health sector they do outreaches on maybe immunisation, and nutrition teaching people on how to get good and well-balanced nutritive food, also prevention of maybe cholera, yeah those issues, but they will never have a specific outreach on FGM to talk about FGM/C."

However, some participants noted that healthcare providers participate in various communitybased and facility-based activities aimed at increasing awareness of FGM/C. These interventions included school health talks, community outreach programmes, community health volunteer (CHV)-led sensitisation, and radio talks. Reliance on $\mathrm{CHVs}$ in part stemmed from challenges in funding and the potential of $\mathrm{CHVs}$ to reach a wider network. Participants also noted the need for providers to leverage other ongoing outreach programmes addressing critical problems in the county. A summary of illustrative quotes describing these activities is provided in Table 14. 
Table 14. Illustrative quotes citing various community- and facility-based FGM/C awareness activities conducted in West Pokot County

\begin{tabular}{|c|c|}
\hline Activity & Illustrative quotes \\
\hline School health talks & $\begin{array}{l}\text { "The strategy that we have actually included is that of creating awareness at the } \\
\text { county level and even at the facility level. Educating schoolchildren for example, } \\
\text { during school health programmes, sometimes we go for school health } \\
\text { programmes and we talk to the girls and the boys on issues of FGM." Public health } \\
\text { nurse, West Pokot County }\end{array}$ \\
\hline Community outreach & $\begin{array}{l}\text { "We also have the community outreaches, outreach advocating against the FGM } \\
\text { basically, talking of these FGM practises, they should be against the FGM } \\
\text { activities." Health administrator, West Pokot County }\end{array}$ \\
\hline $\begin{array}{l}\text { Facility-based FGM/C } \\
\text { health talks }\end{array}$ & $\begin{array}{l}\text { "In terms of advocacy, it has been done very well and people have a lot of } \\
\text { information about FGM and its effects. Many of our health workers engage with } \\
\text { community members in health talks, especially for women when they come for } \\
\text { antenatal, postnatal, and immunisation services." Medical doctor, West Pokot } \\
\text { County Hospital } \\
\text { "What healthcare providers do is to provide information against FGM, it's } \\
\text { consequences, for example it leads to death, haemorrhage, and so forth, and } \\
\text { should not be performed. Health facilities provide health education, sensitisation } \\
\text { and awareness on FGM. They are given information on what they should do as far } \\
\text { as FGM is concerned, disadvantages of FGM, why FGM should not be entertained } \\
\text { in our communities. In case of those who have undergone FGM they are treated } \\
\text { at the facility." Health official, West Pokot County }\end{array}$ \\
\hline $\begin{array}{l}\text { Community health } \\
\text { volunteer-led sensitisation }\end{array}$ & $\begin{array}{l}\text { "We also have community engagement though in the few areas that have } \\
\text { community volunteers, the community strategy system, and we also use them to } \\
\text { pass the FGM/C messages. ... Because of lack of funds, it can hinder the } \\
\text { effectiveness of addressing FGM/C... We are now doing a lot of outreach and } \\
\text { encouraging mothers to come to the hospital, we are giving them tokens if they } \\
\text { come to deliver in the hospitals. .. CHVs in every village are really advocating that } \\
\text { mothers come and deliver at the hospitals." Manager, West Pokot County referral } \\
\text { hospital }\end{array}$ \\
\hline Radio talks & $\begin{array}{l}\text { "We use radio a lot to raise awareness and engage the community on matters } \\
\text { FGM and the need for its abandonment. In these sessions the healthcare providers } \\
\text { clarify why FGM is harmful, especially healthwise, as well as its compromises on } \\
\text { the rights of women and girls." Senior county health official, West Pokot }\end{array}$ \\
\hline
\end{tabular}

\section{Supervision of health facilities and availability of protocols and guidelines}

Table 15 summarises results on supervision from the health facility assessments. Sixteen facilities had supervisory visits within the five weeks preceding the assessment. During the visits, the supervisors observed the delivery of different services (100\%), inquired about service problems $(90 \%)$, examined records (93\%), and made suggestions for improvement (93\%). Most health facilities had general protocols and guidelines, which were used in $83 \%$ of facilities, but none had any protocol on $\mathrm{FGM} / \mathrm{C}$. There was a review of written guidelines and protocols for delivering reproductive health services in the last five years in two-thirds of the facilities (67\%). 
Table 15. Health facility supervision and availability of FGM/C-related prevention protocols/resources $(n=30)$

\begin{tabular}{|c|c|c|c|c|c|c|c|c|}
\hline & \multicolumn{2}{|c|}{ Primary } & \multicolumn{2}{|c|}{ Secondary } & \multicolumn{2}{|c|}{ Tertiary } & \multicolumn{2}{|c|}{ Total } \\
\hline & $\mathbf{n}$ & $\%$ & $\mathbf{n}$ & $\%$ & $\mathbf{N}$ & $\%$ & $\mathbf{n}$ & $\%$ \\
\hline \multicolumn{9}{|l|}{ Last supervisory visit to the facility } \\
\hline$<3$ weeks & 9 & 36.0 & 2 & 50.0 & 0 & 0.0 & 11 & 36.7 \\
\hline 3-5 weeks & 5 & 20.0 & 0 & 0.0 & 0 & 0.0 & 5 & 16.7 \\
\hline $6-21$ weeks & 11 & 44.0 & 2 & 50.0 & 1 & 100.0 & 14 & 46.7 \\
\hline \multicolumn{9}{|l|}{ What the supervisor did } \\
\hline Observed delivery of different services & 25 & 100.0 & 4 & 100.0 & 1 & 100.0 & 30 & 100.0 \\
\hline $\begin{array}{l}\text { Observed only service(s) respondent is } \\
\text { responsible for }\end{array}$ & 10 & 40.0 & 2 & 50.0 & 0 & 0.0 & 12 & 40.0 \\
\hline Inquired about service problems & 22 & 88.0 & 4 & 100.0 & 1 & 100.0 & 27 & 90.0 \\
\hline Examined the records & 23 & 92.0 & 4 & 100.0 & 1 & 100.0 & 28 & 93.3 \\
\hline Made suggestions for improvement & 23 & 92.0 & 4 & 100.0 & 1 & 100.0 & 28 & 93.3 \\
\hline Other & 10 & 40.0 & 0 & 0.0 & 1 & 100.0 & 11 & 36.7 \\
\hline Availability of protocols and guidelines & 21 & 84 & 4 & 100 & 1 & 100 & 26 & 86.7 \\
\hline Protocols on FGM/C & 0 & 0.0 & 0 & 0.0 & 0 & 0.0 & 0 & 0.0 \\
\hline Use of protocols and guidelines & 20 & 80 & 4 & 100 & 1 & 100 & 25 & 83.3 \\
\hline $\begin{array}{l}\text { Review of written guidelines and protocols } \\
\text { for delivering reproductive health services } \\
\text { in the last five years }\end{array}$ & 18 & 72 & 1 & 25 & 1 & 100 & 20 & 66.7 \\
\hline
\end{tabular}

\section{Discussion}

The Kenyan health sector draws its mandate of responding to FGM/C prevention and management from the constitution, various enacted legal and policy frameworks, as well as best global practises. First, the 2010 Constitution of Kenya (Republic of Kenya 2010) contains clauses that protect women and girls from undergoing harmful practices including FGM/C. Specifically, Article 29(c) provides the right not to subject anyone "to any form of violence" or (f) "treated or punished in a cruel, inhuman or degrading manner," while Article 44(3) bars any person from compelling another person to perform, observe, or undergo any cultural practice or rite, thus protecting adults from FGM/C. Similarly, children are protected from undergoing FGM/C in Article 53(d), which provides that any child should not be subjected to abuse, neglect, harmful cultural practices, all forms of violence, inhuman treatment, and punishment. Second, several specific laws address FGM/C including: The Children's Act of 2001, Prohibition of FGM Act of 2011, and Protection Against Domestic Violence Act of 2015. The laws have been aligned to the Constitution as well as provisions from the international and regional legal/human rights instruments that address women's/children's rights, for which Kenya is a signatory.

We found differences between national and county representatives' awareness of FGM/C-related laws and policies, with the latter being less aware of relevant laws and policies. This finding suggests that the law and policymaking process may exclude critical stakeholders including providers and other actors at the county level, with possible implications for the implementation of the laws and policies. This calls for wider engagement of stakeholders when developing and reviewing legal frameworks, as non-involvement may negatively affect the implementation of these laws and policies. 
Policy actors interviewed in this study noted that there are few health-related policies on FGM/C prevention and management. This is despite Kenya, through the Ministry of Health, having developed a reference manual for the management of FGM/C-related complications during pregnancy, childbirth, and the postpartum period in 2007 (MOH 2007). This finding suggests that there is inadequate dissemination of relevant policies within the health sector, which may result in $\mathrm{FGM} / \mathrm{C}$ receiving less attention than other health issues. Furthermore, a disconnect in the policy formulation and dissemination process was noted. These findings are consistent with a desk review report that highlighted the need for the health sector to operationalise the legal/policy frameworks from high-level governance into plans of action/strategies as well as guidelines that are usable at the operational level (Otibho and Kimani 2019).

The findings further demonstrate how the absence of a complete policy-process cycle spanning from formulation to dissemination and implementation resulted in a disconnect in the health sector's response in West Pokot, where implementation of FGM/C prevention reportedly faced challenges because of inadequate knowledge about national FGM/C-related laws and policies. At the operational level, the response was hindered by the lack of tools, notably FGM/C guidelines, protocols and IEC materials to support FGM/C prevention and management. This finding suggests that $\mathrm{FGM} / \mathrm{C}$ is not considered a priority for the health sector.

Despite the prevalence of $\mathrm{FGM} / \mathrm{C}$ being almost universal in West Pokot, the findings revealed that the county health sector lacked data capture or documentation for FGM/C-related cases and complications. While the qualitative results suggested women and girls presented with immediate FGM/C-related complications including bleeding and infections, service data abstraction from antenatal, postnatal, family planning, and youth-friendly care services pointed to a lack of records on women and girls with these complications. Specifically, we did not find records of FGM/C-related immediate, obstetric, gynaecological, sexual and psychological complications in health facilities. This is despite the availability of comprehensive data on women who sought other reproductive health services. The lack of FGM/C data may be attributed to poor operationalisation of health sector-related policies relevant to prevention and management of FGM/C as well as the lack of documentation tools for the operational level. The lack of data may also stem from healthcare providers' limited capacity to identify, manage, and document FGM/C-related cases (Kimani et al. 2018). Consequently, FGM/C indicators are excluded from the HMIS, which limits the availability of evidence to inform programming and investments to address FGM/C. These findings underscore the need for interventions to strengthen healthcare providers' knowledge and skills on identifying, managing, and documenting FGM/C cases, as well as the need to include FGM/C indicators in the HMIS.

Regarding health service delivery readiness in West Pokot, results suggest that the health sector leverages school health, community outreach, community volunteer-led and vernacular radio to boost FGM/C awareness in the community. However, results from client-provider interactions showed that FGM/C-related prevention interventions in health facilities were rare with no individualised education or advice on FGM/C shared with clients. The limited attention to FGM/C may stem from healthcare providers' limited knowledge about FGM/C as well as the low priority placed on the issue by the health sector (Kimani, Muteshi, and Njue 2016; Kimani et al. 2018). Our findings underscore the need to strengthen the delivery of services targeted to women with FGM/C. Given funding constraints, the delivery of FGM/C services may be nested in existing programmes. For example, during our initial preparatory visits to the field we learned that the West Pokot health system is motivating pregnant women to deliver in health facilities through a residential programme for expectant women from hard-to-reach areas. The programme enables women at risk for complications to remain close to the hospital for two weeks to one month until delivery. This programme was noted to promote skilled birthing and to prevent FGM/C among women who may have escaped the cut as girls but would be cut by the traditional birth attendants 
during delivery. Leveraging such a programme to reach women and girls with FGM/C information and services may yield positive results.

With respect to the health workforce, our findings highlighted healthcare providers' limited capacity to effectively manage FGM/C-related complications. The client-provider interactions showed that $90 \%$ of primary and secondary health facilities had providers who lacked the capacity to manage FGM/C complications. These findings point to possible gaps in professional training, inadequacy of the training curriculum to address FGM/C, and lack of continuous professional development modules addressing FGM/C-related complications. It is also an indication of neglect of this important issue within the health sector. This is consistent with recent findings among Somali women in Kenya with FGM/C who reported that they were attended to by providers who displayed some capacity challenges (Kimani et al. 2020). Providers' limited capacity has significant implications for the quality of care received by women and girls living with FGM/C (Evans et al. 2017; Hodes and Creighton 2017; WHO 2016; Zurynski et al. 2015) and can limit heath-seeking (Lazar et al. Shipp, 2013) For example, although best practise guidelines prescribe de-infibulation instead of episiotomy for women with obstructed labour associated with a type-III FGM/C scar (Kimani, Muteshi, and Njue 2016; WHO 2018), our results suggest that providers opt for episiotomies and caesarean sections because they lack training on de-infibulation. Other studies have also highlighted inadequate training of health providers on how to provide care and treatment to women/girls with FGM/C as a critical shortcoming ( Abdulcadir, Rodriguez, and Say 2015; Abdulcadir, Say, and Pallitto 2017; Kimani et al. 2018; Ormrod 2019; Balfour et al. 2016). These findings underscore the need for capacity-building programmes for healthcare providers to enhance the health sector's response to $\mathrm{FGM} / \mathrm{C}$, particularly in high-prevalence settings. In addition, providers should have access to support tools (Zenner et al. 2013) for management of FGM/C-related complications as well as prevention of FGM/C (Doucet, Pallitto, and Groleau 2017; Kimani, Muteshi, and Njue 2016; Rouzi and Alturki 2015). These tools can be useful in addressing gaps in knowledge and skills among healthcare providers.

Findings suggest that women with FGM/C presented with sexual complications including difficulty in penetration, painful intercourse, and lack of enjoyment, as well as psychological consequences evidenced by psycho-trauma and stigmatisation. Surprisingly, however, there was no evidence on what interventions were implemented to address these complications. The findings are consistent with reports that most healthcare providers have challenges in identifying and addressing sexual and psychological complications (Hess, Weinland, and Saalinger 2010; Kimani et al. 2018; Widmark, Tishelman, and Ahlberg 2002; Zaidi et al. 2007). These results underscore the need for FGM/C-related interventions to address sexual and psychological complications (Horowitz and Jackson 1997; Johnsdotter and Essén 2016).

An important aspect of service delivery is a well-functioning referral system (WHO 2007). The results of the health facility assessment showed very high levels of referrals between primary-and tertiary-level facilities, particularly for birth-related, gynaecological, and immediate complications. The referrals mainly stemmed from healthcare providers' limited capacity to handle complications and from infrastructural limitations. The lack of a documentation and audit system for FGM/Crelated referrals suggests that the health system may not meet the norm of availability, accessibility as well as flexibility of response to $\mathrm{FGM} / \mathrm{C}$ in high-prevalence settings where adverse outcomes related to the practice are commonplace (Berg, Denison, and Fretheim 2010). Notably, lack of a well-functioning referral system (Mujasi, Asbu, and Puig-Junoy 2016) has been attributed to an effect on the quality of care for women with reproductive health challenges (Moxey and Jones, 2016) and trust in the healthcare system (Mbanya et al. 2018). Efforts to strengthen the referral system are therefore warranted. 


\section{Limitations}

The study has some limitations; first, healthcare providers who participated in the study might have thought that their general capability to perform their professional work was being assessed and thus presented a more positive picture of their experiences. Nonetheless, we expect that the triangulation of data across qualitative and quantitatively derived results helped to resolve any bias. Second, data on the health system were collected in one setting thus the generalisability of the findings is limited. However, this study adopted a robust approach to investigate the health-system response to FGM/C in terms of prevention and management. Therefore, the data provide a strong foundation for understanding the health system's response FGM/C prevention and management in high-prevalence settings and lays a strong foundation for relevant policy, programming, and investment interventions with the health sector.

\section{Conclusion}

Although the Kenyan health sector's response to FGM/C prevention and the management of women and girls with practice-related complications is anchored in robust legal and policy instruments, the study findings highlight several gaps that may have significant implications for the quality of care received by women and girls who are living with $\mathrm{FGM} / \mathrm{C}$, and for the health sector's capacity to contribute to efforts to promote the abandonment of the practice. First, findings show that although the legal and policy instruments guiding the FGM/C response are well understood at high level governance, providers and other actors at the local level have limited awareness. Second, the health system lacks appropriate systems to capture data on FGM/C-related cases and complications, which limits the availability of evidence to inform policy, programming and investment decisions. Third, implementation of FGM/C interventions is limited by the lack of material, human, and financial resources. For example, healthcare providers lack the capacity to effectively manage many FGM/C-related complications with some, like sexual and psychological complications, being neglected. Taken together, these findings underscore the need to strengthen the health sector's capacity to respond to prevent and manage FGM/C.

\section{Implications for Policy/Programmes/Research}

The study findings highlight several possible avenues for leveraging positive change:

- Stakeholders in different levels of the health systems should be sensitised about laws and policies that address FGM/C prevention and management.

- Tools to guide and support FGM/C-related prevention and management interventions should be developed.

- Healthcare providers should be adequately trained to respond to women and girls with FGM/Crelated complications including birth, and sexual and psychological complications.

- Systems to collect and document data on FGM/C in health facilities should be developed for use in policy, programming, and investment decision-making.

- The referral system for FGM/C-related complications should be strengthened.

- The health system should be adequately integrated and financed to respond to prevention and management of $\mathrm{FGM} / \mathrm{C}$.

- A cost-utility analysis to examine the financial implications of integration of $\mathrm{FGM} / \mathrm{C}$ interventions into the health services is needed. 


\section{References}

Abdulcadir, J., I.M. Rodriguez, and L. Say. 2015. "Research gaps in the care of women with female genital mutilation: An analysis," BJOG: An International Journal of Obstetrics and Gynaecology. https://doi.org/10.1111/1471-0528.13217

Abdulcadir, J., L. Say, and C. Pallitto. 2017. "What do we know about assessing healthcare students and professionals' knowledge, attitude and practice regarding female genital mutilation? A systematic review," Reproductive Health. https://doi.org/10.1186/s12978017-0318-1

Balfour, J., J. Abdulcadir, L. Say, and M.J. Hindin. 2016. "Interventions for healthcare providers to improve treatment and prevention of female genital mutilation: A systematic review," BMC Health Services Research 16(1). https://doi.org/10.1186/s12913-016-1674-1

Behrendt, A. and S. Moritz. 2005. "Posttraumatic stress disorder and memory problems after female genital mutilation," American Journal of Psychiatry. https://doi.org/10.1176/appi.ajp.162.5.1000

Berg, R.C., E. Denison, and A. Fretheim. 2010. "Psychological, social and sexual consequences of female genital mutilation/cutting (FGM/C): A systematic review of quantitative studies," Norwegian Knowledge Centre for Violence and Traumatic Stress Studies. https://doi.org/10.1109/ICECS.2009.53

Berg, R.C., J. Odgaard-Jensen, A. Fretheim, V. Underland, and G. Vist. 2016. "Response to female genital mutilation and obstetric outcomes: Flawed systematic review and metaanalysis does not accurately reflect the available evidence," Obstetrics and Gynecology International. https://doi.org/10.1155/2016/8376260

Berg, R.C., and V. Underland. 2013. Obstetric Consequences of Female Genital Mutilation/Cutting (FGM/C). Oslo: Kunnskapssenteret.

Bruce, J. (1990). Fundamental elements of the quality of care: a simple framework. Studies in family planning, 21(2), 61-91.

Bjälkander, O., L. Bangura, B. Leigh, V. Berggren, S. Bergström, and L. Almroth. 2012. "Health complications of female genital mutilation in Sierra Leone," International Journal of Women's Health. https://doi.org/10.2147//JWH.S32670

Chibber, R., E. El-Saleh, and J. El Harmi. 2011. "Female circumcision: Obstetrical and psychological sequelae continues unabated in the 21st century," Journal of MaternalFetal and Neonatal Medicine. https://doi.org/10.3109/14767058.2010.531318

Doucet, M.H., C. Pallitto, and D. Groleau. 2017. "Understanding the motivations of health-care providers in performing female genital mutilation: An integrative review of the literature," Reproductive Health. https://doi.org/10.1186/s12978-017-0306-5

Evans, C., R. Tweheyo, J. McGarry, J. Eldridge, C. McCormick, V. Nkoyo, and G.M.A. Higginbottom. 2017. "What are the experiences of seeking, receiving and providing FGMrelated healthcare? Perspectives of health professionals and women/girls who have undergone FGM: Protocol for a systematic review of qualitative evidence," BMJ Open. https://doi.org/10.1136/bmjopen-2017-018170

Frerichs, R. R. (1989). Simple analytic procedures for rapid microcomputer-assisted cluster surveys in developing countries. Public health reports, 104(1), 24. 
Frerichs, R. R., and Tar, K. T. (1989). Computer-assisted rapid surveys in developing countries. Public health reports, 104(1), 14.

Gale, N.K., G. Heath, E. Cameron, S. Rashid, and S. Redwood. 2013. "Using the framework method for the analysis of qualitative data in multi-disciplinary health research," $B M C$ Medical Research Methodology. https://doi.org/10.1186/1471-2288-13-117

Her Majesty's Stationery Office (HMSO). 2004. Children Act c. 31. London: HMSO. Available at: http://www.legislation.gov.uk/ukpga/2004/31/contents

Hess, R.F., J.A. Weinland, and N.M. Saalinger. 2010. "Knowledge of female genital cutting and experience with women who are circumcised: A survey of nurse-midwives in the United States," Journal of Midwifery and Women's Health. https://doi.org/10.1016/j.jmwh.2009.01.005

Hodes, D. and S.M. Creighton. 2017. "Setting up a clinic to assess children and young people for female genital mutilation," Archives of Disease in Childhood. Education and Practice Edition 102(1). https://doi.org/10.1136/archdischild-2016-311296

Horowitz, C.R. and J.C. Jackson. 1997. “Female 'circumcision': African women confront American medicine," Journal of General Internal Medicine 12(8): 491-499. https://doi.org/10.1046/j.1525-1497.1997.00088.x

Johnsdotter, S. and B. Essén. 2016. "Cultural change after migration: Circumcision of girls in Western migrant communities," Best practice and Research. Clinical Obstetrics and Gynaecology 32: 15-25. https://doi.org/10.1016/j.bpobgyn.2015.10.012

Kaplan, A., S. Hechavarría, M. Martín, and I. Bonhoure. 2011. "Health consequences of female genital mutilation/cutting in the Gambia, evidence into action," Reproductive Health. https://doi.org/10.1186/1742-4755-8-26

Kenya Master Health Facility List (KMHFL) 2017. Ministry of Health. Retrieved from: http://kmhfl.health.go.ke/\#/home

Kenya National Bureau of Statistics, Ministry of Health/Kenya, National AIDS Control Council/Kenya, Kenya Medical Research Institute, National Council for Population and Development/Kenya, and ICF International. 2015. Kenya Demographic and Health Survey 2014. Rockville, MD: Kenya National Bureau of Statistics, Ministry of Health/Kenya, National AIDS Control Council/Kenya, Kenya Medical Research Institute, National Council for Population and Development/Kenya, and ICF International.

Kimani, S., T. Esho, V. Kimani, S. Muniu, J. Kamau, C. Kigondu, ... J. Guyo. 2018. "Female genital mutilation/cutting: Innovative training approach for nurse-midwives in high prevalent settings," Obstetrics and Gynecology International. https://doi.org/10.1155/2018/5043512

Kimani, S., and C. Kabiru. 2018. Shifts in Female Genital Mutilation/Cutting in Kenya: Perspectives of Families and Health Care Providers. Evidence to End FGM/C: Research to Help Girls and Women Thrive. New York: Population Council. Available at: https://knowledgecommons.popcouncil.org/departments_sbsr-rh/561/

Kimani, S., C. Kabiru, J. Muteshi, and J. Guyo. 2020. "Exploring barriers to seeking health care among Kenyan Somali women with female genital mutilation: A qualitative study," BMC International Health and Human Rights 6: 1-12.

Kimani, S., J. Muteshi, and C. Njue. 2016. Health Impacts of Female Genital Mutilation/Cutting: A Synthesis of the Evidence. Evidence to End FGM/C Programme: Research to Help Girls 
and Women Thrive. New York: Population Council. Available at:

https://knowledgecommons.popcouncil.org/departments_sbsr-rh/637/

Lazar, J.N., C.E. Johnson-Agbakwu, O.I. Davis, and M. P.-L. Shipp. 2013. "Providers' perceptions of challenges in obstetrical care for Somali women," Obstetrics and Gynecology International. https://doi.org/10.1155/2013/149640

Mbanya, V.N., A.A. Gele, E. Díaz, and B. Kumar. 2018. "Health care-seeking patterns for female genital mutilation/cutting among young Somalis in Norway," BMC Public Health. https://doi.org/10.1186/s12889-018-5440-7

Miller, R. A., Fisher, A. A., Miller, K., Ndhlovu, L., Maggwa, B. N., Askew, I., ... and Tapsoba, P. (1997). The situation analysis approach to assessing family planning and reproductive health services: a handbook.

Ministry of Health/Kenya (MOH). 2007. Management of Complications, Pregnancy, Childbirth and the Postpartum Period in the Presence of FGM/C. Nairobi: MOH.

2015. "National Adolescent Sexual and Reproductive Policy 2015." Nairobi: MOH.

Moxey, J.M., and L.L. Jones. 2016. "A qualitative study exploring how Somali women exposed to female genital mutilation experience and perceive antenatal and intrapartum care in England," BMJ Open 6(1). https://doi.org/10.1136/bmjopen-2015-009846

Mujasi, P.N., E.Z. Asbu, and J. Puig-Junoy. 2016. "How efficient are referral hospitals in Uganda? A data envelopment analysis and tobit regression approach," BMC Health Services Research. https://doi.org/10.1186/s12913-016-1472-9

National Council for Law Reporting. 2011. Prohibition of Female Genital Mutilation Act (32): 514. Available at: http://kenyalaw.org/kl/fileadmin/pdfdownloads/Acts/ProhibitionofFemaleGenitalMutilation Act_No32of2011.pdf

Njue, C. and I. Askew. 2004. Medicalization of Female Genital Cutting Among the Abagusii in Nyanza Province, Kenya, Frontiers in Reproductive Health Program. Washington, DC: Population Council. Available at: https://knowledgecommons.popcouncil.org/departments_sbsr-rh/32/

Ormrod, J. 2019. "The experience of NHS care for women living with female genital mutilation," British Journal of Nursing 28(10). https://doi.org/10.12968/bjon.2019.28.10.628

Otibho, O., and S. Kimani. 2019. Exploring the Nigerian health system's response to female genital mutilation/cutting. Nairobi: Population Council. Available at: https://knowledgecommons.popcouncil.org/departments_sbsr-rh/549/

Republic of Kenya. 2010. The Constitution of Kenya. Kenya Law Reports (February): 31.

Available at: www.kenyalaw.org 2011. Nurses Amendment Act 2011. Cap 257. Nairobi. 2012a. Medical and Dentists Act. 2012. Cap 253, 36 §. Nairobi. 2012b. Penal Code Chapter 63, (1). Nairobi. Available at: www.kenyalaw.org 2015. The Protection Against Domestic Violence Act. Kenya Gazette May 19: 13-27. Available at: http://kenyalaw.org/kl/fileadmin/pdfdownloads/Acts/ProtectionAgainstDomesticViolenceA ct_2015.pdf

2018. National School Heath Policy. Nairobi. 
Ritchie, J., J. Lewis, C.M. Nicholls, and R. Ormston. 2013. Qualitative Research Practice: A Guide for Social Science Students and Researchers. London: SAGE Publications.

Rivero-Fuentes, M., S. Ramarao, R. Estrada, C. Warren, S. Mullick, H. Birungi, I. Askew, and J.M.S. Townsend. 2008. Assessing Integration Methodology (AIM): A Handbook for Measuring and Assessing the Integration of Family Planning and Other Reproductive Health Services. Washington, DC: Population Council.

Rouzi, A.A. and F. Alturki. 2015. "Female genital mutilation/cutting: An update," Clinical and Experimental Obstetrics and Gynecology https://doi.org/10.12891/ceog1823.2015

UNICEF. 2016. "Female Genital Mutilation/Cutting: A Global Concern." Factsheet. New York: UNICEF.

Vloeberghs, E., A. Van Der Kwaak, J. Knipscheer, and M. Van Den Muijsenbergh. 2012. "Coping and chronic psychosocial consequences of female genital mutilation in the Netherlands," Ethnicity and Health. https://doi.org/10.1080/13557858.2013.771148

Whitehorn, J., O. Ayonrinde, and S. Maingay. 2002. "Female genital mutilation: Cultural and psychological implications," Sexual and Relationship Therapy. https://doi.org/10.1080/14681990220121275

Widmark, C., C. Tishelman, and B.M. Ahlberg. 2002. "A study of Swedish midwives' encounters with infibulated African women in Sweden," Midwifery 18(2): 113-125. https://doi.org/10.1054/midw.2002.0307

World Health Organization. 2006. "Female genital mutilation and obstetric outcome: WHO collaborative prospective study in six African countries," Lancet. https://doi.org/10.1016/S0140-6736(06)68805-3

2007. Everybody's Business: Strengthening Health Systems to Improve Health Outcomes. WHO's Framework for Action. Geneva: WHO

2008. "Eliminating Female Genital Mutilation: An Interagency Statement." Geneva: WHO.

2016. WHO Guidelines on the Management of Health Complications from Female Genital Mutilation. Geneva: WHO. Available at: http://apps.who.int/iris/bitstream/10665/206437/1/9789241549646_eng.pdf?ua=1

2018. Care of Girls and Women Living with Female Genital Mutilation: A Clinical Handbook. Geneva: WHO

Yoder, P. S., Wang, S., and Johansen, E. (2013). Estimates of female genital mutilation/cutting in 27 African countries and Yemen. Studies in family planning, 44(2), 189-204.

Zaidi, N., A. Khalil, C. Roberts, and M. Browne. 2007. "Knowledge of female genital mutilation among healthcare professionals," Journal of Obstetrics and Gynaecology. https://doi.org/10.1080/01443610601124257

Zenner, N., L.M. Liao, Y. Richens, and S.M. Creighton. 2013. "Quality of obstetric and midwifery care for pregnant women who have undergone female genital mutilation," Journal of Obstetrics and Gynaecology. https://doi.org/10.3109/01443615.2013.767785

Zurynski, Y., P. Sureshkumar, A. Phu, and E. Elliott. 2015. "Female genital mutilation and cutting: A systematic literature review of health professionals' knowledge, attitudes and clinical practice," BMC International Health and Human Rights. https://doi.org/10.1186/s12914015-0070-y 